\title{
BMJ Global Health Traditional, complementary and alternative medicine use in Sub-Saharan Africa: a systematic review
}

\author{
Peter Bai James, ${ }^{1,2}$ Jon Wardle, ${ }^{1}$ Amie Steel, ${ }^{1,3}$ Jon Adams ${ }^{1}$
}

To cite: James PB, Wardle J, Steel A, et al. Traditional, complementary and alternative medicine use in SubSaharan Africa: a systematic review. BMJ Glob Health 2018;3:e000895. doi:10.1136/ bmjgh-2018-000895

Handling editor Dr Stephanie M Topp

- Additional material is published online only. To view please visit the journal online (http://dx.doi.org/10.1136/ bmjgh-2018-000895).

Received 14 April 2018 Revised 26 August 2018 Accepted 27 August 2018

Check for updates

(c) Author(s) (or their employer(s)) 2018. Re-use permitted under CC BY-NC. No commercial re-use. See rights and permissions. Published by BMJ

${ }^{1}$ Australian Research Centre in Complementary and Integrative Medicine, Faculty of Health, University of Technology Sydney, Sydney, New South Wales,

Australia

${ }^{2}$ Faculty of Pharmaceutical Sciences, College of Medicine and Allied Health Sciences, University of Sierra Leone, Freetown, Sierra Leone ${ }^{3}$ Office of Research, Endeavour College of Natural Health, Brisbane, Queensland, Australia

Correspondence to Peter Bai James; Peter.B.James@student.uts. edu.au

\section{ABSTRACT}

Background The WHO estimates that a considerable number of people in Sub-Saharan Africa (SSA) rely on traditional, complementary and alternative medicine (TCAM) to meet their primary healthcare needs, yet there remains a dearth of research evidence on the overall picture of TCAM utilisation in the region.

Methods We conducted a literature search of original articles examining TCAM use in SSA between 1 January 2006 and 28 February 2017, employing Medline, Cumulative Index to Nursing and Allied Health Literature, Allied and Complementary Medicine Database, Scopus, ProQuest, PubMed, Embase and African Journals Online databases. A critical appraisal of relevant articles reporting a quantitative or mixed-method design was undertaken.

Results Despite the heterogeneity and general low quality of the identified literature, the review highlights a relatively high use of TCAM alone or in combination with orthodox medicine, in both general population and in specific health conditions in SSA. TCAM users compared with non-TCAM users are more likely to be of low socioeconomic and educational status, while there were inconsistencies in age, sex, spatial location and religious affiliation between TCAM users and non-TCAM users. Most TCAM users (55.8\%-100\%) in SSA fail to disclose TCAM use to their healthcare providers, with the main reasons for non-disclosure being fear of receiving improper care, healthcare providers' negative attitude and a lack of enquiry about TCAM use from healthcare providers. Conclusion TCAM use in SSA is significant, although most studies emerge from a few countries. Factors associated with TCAM use in SSA are similar to those observed in other regions, but further research may be required to further elucidate challenges and opportunities related to TCAM use specific to SSA.

\section{INTRODUCTION}

Traditional, complementary and alternative medicine (TCAM) refers to a set of healthcare practices (indigenous or imported) that are delivered outside of the mainstream healthcare system. ${ }^{1}$ In the African setting it may encompass local herbal medicines or products, indigenous healthcare practices (traditional bone setting), as well as imported complementary and alternative medicine

\section{Key questions}

What is already known?

- There remains a dearth of research evidence in SubSaharan Africa (SSA) on the drivers and facilitators of traditional, complementary and alternative medicine (TCAM) use, factors associated with TCAM use, and the impact of TCAM use on broader healthcare.

\section{What are the new findings?}

- Studies suggest a high use of TCAM (particularly TCAM products) in SSA, although most studies are limited to few countries, and there is a significant heterogeneity and low quality of some of the current scholarship.

- TCAM is used due to its perceived low cost, alignment of TCAM with sociocultural, religious and spiritual values, and dissatisfaction with conventional healthcare.

- Non-disclosure of TCAM use to healthcare providers is common among TCAM users in SSA, primarily due to the fear of receiving improper care from hospitals, negative attitude of healthcare providers towards TCAM and a lack of enquiry about TCAM use from healthcare providers.

What do the new findings imply?

- Widespread TCAM use in SSA necessitates health departments and governments across the region to consider and familiarise themselves with the current role of TCAM and its future possibilities within the wider healthcare system.

products and practices (eg, acupuncture or chiropractic). Sub-Saharan Africa is one region of the world in which TCAM has long been held to be widespread, with a considerable number of its population relying on it to maintain their health or prevent and treat communicable and non-communicable diseases. ${ }^{2}{ }^{3}$ The economic influence of TCAM is extensive, contributing at least R2.9 billion (US\$2.2 million) to the South African economy alone. ${ }^{4}$

The increasing uptake of TCAM services across the continent in recent decades has attracted the attention of policy makers, 
researchers and healthcare professionals. In the past 20 years, the WHO regional office for Africa spearheaded the implementation of a regional strategy endorsed by African Heads of State in Lusaka, Zambia ${ }^{5}$ to promote the role of TCAM in health systems in the African region. The gains experienced since the adoption of the regional plan include policy formation in 36 countries and research promotion, including the establishment of TCAM research centres in some countries like Nigeria, Ghana and South Africa. The regional plan has also promoted the inclusion of TCAM courses into the curricula of healthcare training institutions in countries across the continent. For instance, such plan has seen the inclusion of TCAM courses in some South African ${ }^{6}$ and Ghanian ${ }^{7}$ universities. It has also promoted the training of TCAM practitioners and the local production and cultivation of medicinal plants, as well as the establishment of intellectual property rights for traditional medicine knowledge in few nations. ${ }^{5}$ Despite such progress, African countries continue to grapple with an absence of TCAM policy or its implementation, inadequate TCAM research infrastructure and insufficient regulation of TCAM products and practices. ${ }^{58}$ For instance, by 2005 , only $32 \%$ and $27 \%$ of the African countries who responded to the WHO global survey had a national policy and law or regulation on TCAM. ${ }^{9}$

A steady rise in the prevalence of chronic non-communicable diseases is significantly contributing to Africa's disease burden, and is adding burden to healthcare systems already strained due to the high incidence of infectious diseases. ${ }^{10}$ With high TCAM use for chronic health conditions reported outside of Africa, ${ }^{11}$ it is postulated that TCAM will play an integral role in the health and well-being of people suffering from chronic diseases in Africa as well. ${ }^{12}{ }^{13}$ TCAM's role in the provision of primary healthcare is recognised in some Sub-Saharan Africa countries' health policy documents within the context of limited access to essential health services, especially among the rural poor. ${ }^{1415}$

Considering the high utilisation of TCAM across Sub-Saharan Africa, it is necessary for policy decision makers, researchers and health professionals to recognise TCAM healthcare practices as integral to the health-seeking of populations and develop an effective response that safeguards their health and well-being. A proper policy and practice response to increasing TCAM use requires an indepth insight into the nature of TCAM use, including the profile of TCAM users as well as the drivers and barriers that facilitate and limit the use of TCAM. In direct response, this paper reports findings from the first comprehensive critical review of the prevalence of TCAM use alone and in combination with conventional medicine, sociodemographic characteristics of TCAM users, motivators of and barriers to TCAM use, safety and cost associated with TCAM use, as well as details around non-disclosure of TCAM use to health providers.

\section{METHODOLOGY}

\section{Research design}

The systematic review analyses the contemporary scholarship using an established approach developed for a number of health research topics. ${ }^{16-18}$

\section{Search strategy}

Peer-reviewed articles reporting on TCAM use in Sub-Saharan Africa were searched using the following databases: Cumulative Index to Nursing and Allied Health Literature, Allied and Complementary Medicine Database, Scopus, ProQuest, Medline, PubMed, African Journals Online, Embase and Google Scholar. Hand searching in the bibliography of relevant articles was also employed to help ensure the capture of all relevant peer-reviewed literature. Table 1 shows a summary of the search strategy employed. The definition of TCAM in our review was based on the definitions of traditional medicine and complementary medicine put forward by WHO. ${ }^{1}$ It encompasses local herbal medicines or products, indigenous healthcare practices (traditional bone setting), as well as imported complementary and alternative medicine products and practices (such as Chinese medicine and chiropractic). Vitamins and mineral supplements were not considered as TCAM products in our study, as these are usually used for general health prevention rather than for specific health purposes.

The results from the databases and hand searches were imported into EndNote V.X8. Duplicates were removed, and the remaining articles were screened based on the title, abstract and full text. Figure 1 gives a detailed algorithm of how papers were excluded and included.

\section{Search outcomes}

We initially identified 1916 articles from the database search and from other sources. These papers were further screened using our inclusion criteria. One hundred and eighty papers met the inclusion criteria and were included in the critical review. A summary of the search process and categorical analysis of the reviewed studies are shown in figure 1 and online supplementary file 1 , respectively.

\section{Quality appraisal system}

We employed an analytical tool adapted from previous critical reviews on complementary and alternative medicine use $\mathrm{e}^{1719}$ to evaluate the quality of the papers that met the review criteria. The tool appraised study methodology, participant characteristics and TCAM use, with 1 point given to each aspect under the three domains (methodology, reporting of participant characteristics and reporting TCAM use). A maximum potential score of 12 was tallied if all aspects of the three domains were met. Two authors separately analysed and allocated scores. Differences in the final score were resolved through discussion among the four authors, with the most senior author having to make the final decision. Only articles using mixed and quantitative designs were considered 
Table 1 Search strategy

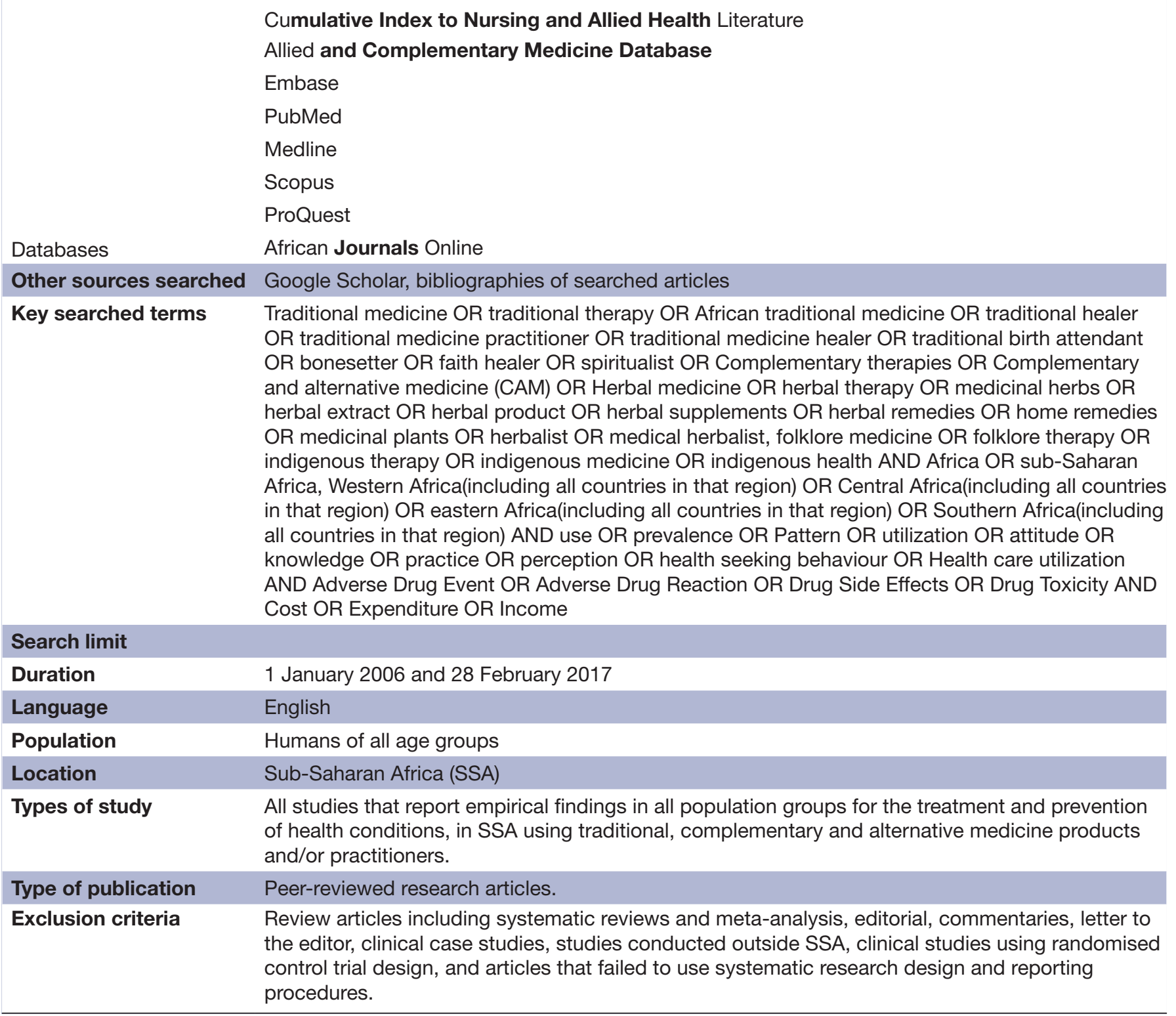

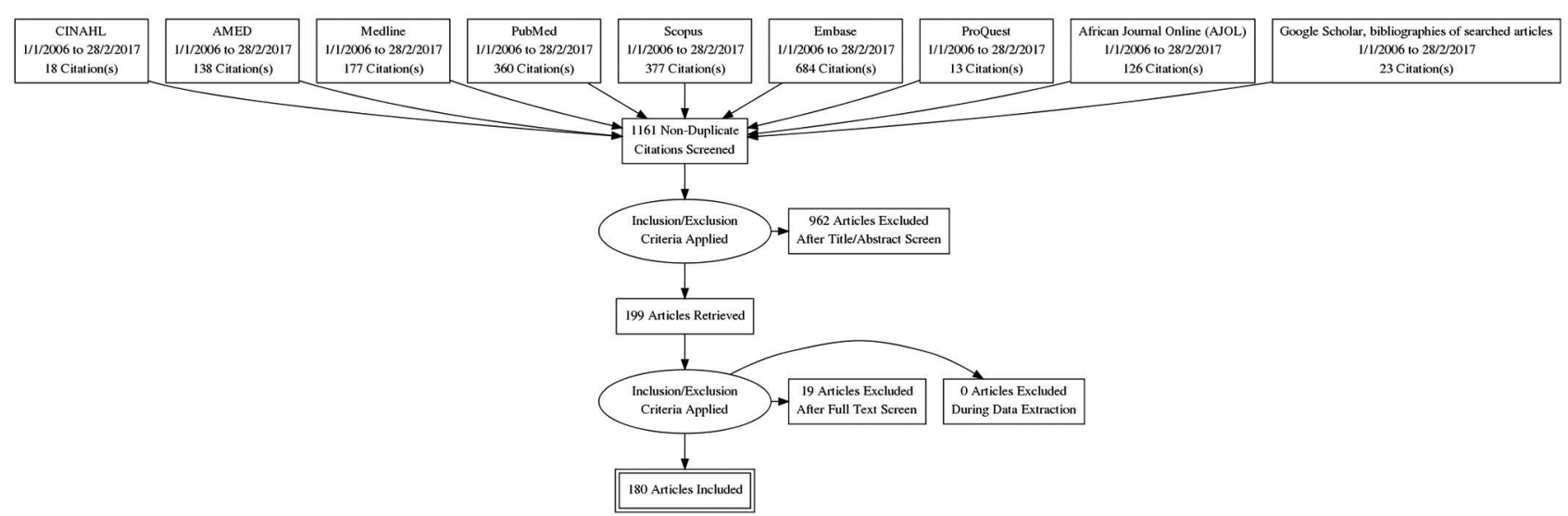

Figure 1 PRISMA flow diagram of included and excluded articles. AMED, Allied and Complementary Medicine Database; CINAHL, Cumulative Index to Nursing and Allied Health Literature. 
Table 2 Quality appraisal scoring system

\begin{tabular}{|lll}
\hline Dimensions of quality appraisal & Codes & $\begin{array}{l}\text { Points } \\
\text { awarded }\end{array}$ \\
\hline Methodology & & \\
\hline Representative sampling strategy & A & 1 \\
\hline Sample size $\geq 500$ & B & 1 \\
\hline Response rate $>75 \%$ & C & 1 \\
\hline Low recall bias on TCAM use & D & 1 \\
within the past 12 months or less & & \\
\hline
\end{tabular}

Reporting participants'

characteristics

\begin{tabular}{|lll|}
\hline Age & E & 1 \\
\hline Gender & F & 1 \\
\hline $\begin{array}{l}\text { Socioeconomic status (income or } \\
\text { education) }\end{array}$ & $\mathrm{G}$ & 1 \\
\hline $\begin{array}{l}\text { Ethnicity/tribe } \\
\text { Location (urban or rural or district }\end{array}$ & $\mathrm{I}$ & 1 \\
$\begin{array}{l}\text { or region) } \\
\text { Reporting TCAM use }\end{array}$ & 1 \\
\hline $\begin{array}{l}\text { Definition of TCAM to respondents } \\
\text { Assessed use of TCAM }\end{array}$ & $\mathrm{J}$ & 1 \\
\hline Type of TCAM & $\mathrm{L}$ & 1 \\
\hline Total & & 12 \\
\hline
\end{tabular}

TCAM, traditional, complementary and alternative medicine.

as they formed the greater part of the reviewed papers. For mixed-method studies, only the quantitative study component was appraised. Table 2 and the online supplementary file 2 provide the details of the quality appraisal tool and the summated score of each paper, respectively. Articles with summated scores ranging from 9 to $12,6-8$ and $0-5$ were considered of good, fair and poor quality, respectively.

\section{RESULTS}

A total of 180 articles met the criteria for review. The included articles employed mixed-method $(n=14)$, qualitative $(n=12)$ and quantitative $(n=154)$ research designs. Based on our search strategy, we were able to identify studies from 25 out of the total 48 countries which constitute Sub-Saharan Africa. Nearly three-quarters (72.8\%) of included papers reported research conducted in just four countries: Nigeria $(\mathrm{n}=72,40.0 \%)$, South Africa $(n=26,14.4 \%)$, Ghana $(n=20,11.1 \%)$ and Uganda $(n=13$, $7.2 \%)$. A summary of the included articles is shown in online supplementary file 1 . There were very few articles with high methodological quality. Of the 165 articles that met the requirement for critical appraisal, 2 articles from South Africa ${ }^{20}$ had a total score of 11 , and 7 papers from different countries had a score of $10 .{ }^{22-28}$ Less than a quarter $(n=30,18.2 \%)$ and close to two-thirds $(n=106$, $64.2 \%$ ) of the articles appraised had total scores ranging from 9 to 12 and from 6 to 8 , respectively. Methodological flaws were discovered in the selected articles, with only 8 $(4.8 \%)$ of studies employing a nationally representative sampling strategy. Two-thirds $(\mathrm{n}=110,66.7 \%)$ of the identified articles reported a sample size less than 500. Also, the tendency for recall bias based on whether TCAM was used within the past 12 months or less was identified in almost half $(\mathrm{n}=82,49.7 \%)$ of the papers appraised. With regard to the reporting of TCAM use, close to two-thirds $(66.1 \%)$ of the articles reviewed failed to provide a definition of TCAM. Details of the results of the critical appraisal scoring system are shown in online supplementary file 2 . In general, the reviewed articles reported eight major themes: types of TCAM used, prevalence of use of TCAM, prevalence of concurrent use of TCAM and allopathic medicine, and sociodemographic profile of TCAM users, drivers and barriers to TCAM use, non-disclosure of TCAM use to healthcare providers, TCAM costs and reported adverse effects of TCAM use. In reporting the findings of our review, the prevalence of TCAM and the sociodemographic profile of TCAM users were categorised into general population studies (including both adult male and adult female participants and not limited to examining any single specific disease or condition) and subhealth or disease-specific populations. The categorisation was done to highlight the TCAM utilisation in the general population and in diseases or conditions and specific populations that are considered a public health or clinical issue in Sub-Saharan Africa. Disease conditions or populations with single publication were grouped as others.

\section{Types of TCAM use}

Based on the literature reviewed, biological-based therapies such as herbal therapy are the most common TCAM used in Sub-Saharan Africa, followed by faith-based healing methods (prayer/spirituality) and mind-body therapies (massage, traditional bone setting relaxation, mediation and yoga) ${ }^{29-53} \mathrm{~A}$ few studies examining TCAM use among university staff, patients with HIV/AIDS and patients with cancer reported homeopathy, ${ }^{54}$ prayer/ spirituality $^{2155}$ and massage ${ }^{56}$ as the most common TCAM modalities used, respectively.

\section{Prevalence of TCAM use in Sub-Saharan Africa}

One hundred and twenty-six of the reviewed articles reported the prevalence of TCAM product (self-care and over-the-counter use) and practitioner use. Papers were divided into two main categories: those reporting TCAM use in the general population (including both adult male and adult female participants and not limited to examining any single specific disease or condition) and TCAM use in subpopulations (such as a specific clinical population). For reporting TCAM prevalence, articles were categorised as reporting on large sample studies $(n \geq 500)$ and small sample studies $(\mathrm{n}<500)$. In general, the current literature suggests a varied prevalence but substantial use of TCAM in both general and subhealth populations 
(despite methodological limitations in many of the articles reviewed, including no formal or standardised definition of timeframe of use).

\section{Prevalence of TCAM use in the general population}

Twenty-six articles reported TCAM product use in the general population, ${ }^{12} 4445484957-77$ reporting substantial prevalence rates ranging from $4.6 \%$ (urban settlement in Ethiopia) ${ }^{65}$ to $94 \%$ (semiurban settlements in Nigeria and Ethiopia), ${ }^{49}$ with an estimated average of $58.2 \%$. At least half $(n=23)$ of the study population in majority of the studies reported using TCAM products. Similar utilisation rates were observed among large sample size $(\geq 500)$ studies $^{444557-60656876}$ and small sample size $(<500)$ studies. ${ }^{12} 484961-64666769-75$

A varied prevalence was also observed among the 10 articles $^{20} 27285863$ 78-81 that reported on TCAM practitioner utilisation $(1.2 \%-67 \%$ (mean, $28.8 \%)$ ). Among studies with large samples, ${ }^{2027} 28579$ a lower use of TCAM practitioner services was observed $(1.2 \%-44.1 \%$ (average, 12.6\%)) compared with studies ${ }^{63} 788081$ with smaller samples $(37.5 \%-67 \%$ (mean, $53.0 \%)$ ).

\section{Prevalence of TCAM use in health subpopulations}

Pregnancy, childbirth, abortion and infertility

Eighteen studies reported the prevalence rates of TCAM use during pregnancy, ${ }^{2482-95}$ childbirth $^{94-96}$ and for pregnancy termination. ${ }^{97}$ Between $12 \%$ and $90.3 \%$ (mean, $48.4 \%$ ) of pregnant women were reported to use a TCAM product during pregnancy, a rate consistent across studies drawn from large sample sizes ${ }^{84} 8593-95$ (25.5\%-67.5\% (average, $45.3 \%)$ ) and from small sample sizes ${ }^{24} 8386-92$ $(12 \%-90.3 \%$ (average, $50.1 \%))$. There is limited literature concerning TCAM practitioner service utilisation during pregnancy, with only one Zambian ${ }^{82}$ and Nigerian $^{98}$ study reporting the proportion of women seeking the service of a traditional medicine practitioner during their pregnancy (Zambia: 21\%; Nigerian: 44.6\%). A study of Ghanaian women ${ }^{94}(\mathrm{n}=611)$ reported $11.7 \%$ used TCAM products during childbirth, while two Nigerian studies reporting large sample sizes identified $24.1 \%$ and $42.5 \%$ of postpartum women used the services of TCAM practitioners during childbirth, respectively. ${ }^{95}$ Close to a quarter $(22 \%)$ of urban Tanzanian women seek help from a traditional medicine practitioner for pregnancy termination compared with $16.9 \%$ of their rural counterparts. ${ }^{97}$ There is also a limited literature with regards TCAM use for infertility, with only one Ugandan study reporting high use $(76.2 \%)$ of herbal medicine among women seeking infertility care ${ }^{99}$ and a Nigerian study reporting high use (69\%) of TCAM practitioner service among infertile couples. ${ }^{100}$ There is also a dearth of research evidence of TCAM use among menopausal women, with only one Nigerian study reporting a lower use $(3.8 \%)$ TCAM practitioner service among menopausal women. ${ }^{101}$

\section{Sexual health conditions}

Three papers, of which two were drawn from large sample sizes $(\geq 500)$, reported Zambian $(68 \%)$ women used TCAM products to dry up and constrict the vaginal passage prior to sexual intercourse, ${ }^{102}$ and Ghanaian $(56.3 \%)$ women used TCAM to manage gynaecological conditions. ${ }^{94}$ The third study $(\mathrm{n}=224)$ reported $54.9 \%$ of male and female Ugandans presenting with various types of sexually transmitted infections used TCAM. ${ }^{103}$

\section{Hypertension, diabetes, cancer and asthma}

Seven articles reported TCAM product utilisation rates among patients with hypertension ${ }^{32} 333946104-106$ and indicate a rate of between $19.5 \%$ and $67.8 \%$ (mean, $27.1 \%$ ). Only one of the seven studies was drawn from a large sample of patients with hypertension $(n=500)$ and the reported prevalence in this case was $24 \% .{ }^{106}$

TCAM product use by patients with diabetes varied across the four identified studies drawn from smaller samples, with a higher rate reported in Tanzania $(77.1 \%)^{107}$ compared with Nigeria $(46 \%),{ }^{43}$ Guinea $(33 \%)^{108}$ and Kenya (12.4\%). ${ }^{109}$ With regard to cancer, the available literature reports a high use of TCAM among patients with cancer in Sub-Saharan Africa (Nigeria: $65 \%^{34}$; Ethiopia: $79 \%{ }^{110}$; Ghana: $73.5 \%{ }^{56}$ ), although one Nigerian study did report a lower rate of use specifically for TCAM services. ${ }^{11}$ A Prospective Urban and Rural Epidemiological (PURE) study in South Africa reported a higher $(61 \%)$ TCAM product use among general adult population with non-communicable diseases. ${ }^{12}$ With regard to TCAM use among patients with asthma, the reviewed literature was drawn from smaller sample size studies conducted in Nigeria, and they suggested that slightly over half of adult $(50.5 \%)^{29}$ and a quarter of paediatric $(25 \%)^{47}$ patients were TCAM product users.

\section{HIV/AIDS}

Twenty-four papers reported TCAM product ${ }^{112}$ and practitioner ${ }^{113-115}$ usage among patients with HIV/AIDS. We observed a similar average prevalence of TCAM product $(1.8 \%-96.8 \%$ (mean, $45.8 \%))$ and practitioner use $(17.6 \%-62 \%$ (mean, $45.0 \%)$ ), respectively. Only one product-based $^{59}$ and one practitioner-based ${ }^{113}$ studies were conducted using a large sample of patients with HIV/AIDS, and both reported utilisation rates of $1.8 \%$ and $62 \%$, respectively.

\section{Malaria and febrile illness}

A total of eight papers reported TCAM use for malaria and febrile illness, with close to a quarter of children and at least half of adults reported using TCAM. ${ }^{22}$ 116-122 Two studies reporting large sample sizes in Sierra Leone reported $22 \%{ }^{121}$ and $24.7 \%{ }^{22}$ TCAM products use among children, while the rates were higher among adult populations in Sierra Leone $(55 \%)^{120}$ and Ghana $(50.3 \%) .{ }^{119}$ An increased rate of TCAM use for uncomplicated malaria was recorded in Mali ${ }^{117}$ between 2003 (24\%) and $2013(58 \%)$. Another large population study in two rural districts in Mali documented 27\% of individuals with uncomplicated malaria used TCAM alone for management of their health compared with $50 \%$ for complicated 
cases. ${ }^{116}$ On the other hand, a lower proportion (18.2\%) of TCAM products was reported among 33 children with complicated malaria ${ }^{122}$ The only study reporting TCAM practitioner use for malaria was conducted in Nigeria and reported a prevalence of $49.7 \% .^{118}$

\section{Mental and neurological disorders (epilepsy and mental health disorders)}

A total of 11 articles reporting small sample sizes $(<500)$ identified rates of TCAM use among patients with epilepsy $^{40} 47123$ and mental health conditions. ${ }^{23}$ 124-131 Among children with epilepsy, Lagunju ${ }^{40}$ reported a high use $(56.6 \%)$ of TCAM products compared with $38 \%$ reported by Oshikoya et al. ${ }^{47}$ On the other hand, Nwani et $a l^{123}$ reported a high utilisation of TCAM practitioner service $(65.5 \%)$ among adult patients with epilepsy. Seventy-six per cent of Nigerian patients with schizophrenia ${ }^{129}$ and $11.5 \%$ of patients with psychosis in South Africa ${ }^{131}$ used TCAM products. Among psychiatric patients in general, a higher proportion in Nigeria $(73.5 \%)^{125}$ and Ethiopia $(50.3 \%)^{23}$ used the service of a TCAM practitioner compared with their counterparts (in Ghana $(23.3 \%)^{127}$ and Malawi $(22.7 \%)^{128}$ ). Greater than two-thirds $(69 \%-76 \%)$ of patients with schizophrenia in Nigeria ${ }^{124} 129$ seek care from a TCAM practitioner, whereas a lower proportion of patients with psychosis $(11.5 \%-38.5 \%)$ in South Africa ${ }^{126} 131$ visit a TCAM practitioner. On the other hand, a Ugandan study stated that more than $80 \%$ of patients with psychosis simultaneously access both orthodox and traditional medicine systems. ${ }^{132}$ In Sudan, more than one-third $(41 \%)$ of patients with mental disorders had sought the service of a TCAM practitioner prior to accessing conventional care. ${ }^{130}$

\section{Musculoskeletal conditions}

A total of seven (six Nigerian, one Ghanaian) studies drawn from small samples reported TCAM product and practitioner use for musculoskeletal conditions. Two studies reported $96.8 \%$ of peasant farmers ${ }^{41}$ and $40.2 \%$ of occupational drivers ${ }^{133}$ as using TCAM products for the management of musculoskeletal pain. Another study reported $47.2 \%$ of TCAM product use among patients with osteoarthritis. ${ }^{42}$ On the other hand, $52.3 \%, 31.6 \%$ and $21 \%$ of patients with bone fracture from north central $^{134135}$ and middle belt ${ }^{136}$ regions of Nigeria patronises traditional bonesetters (TBS), respectively. In the Ghanaian study, 29 of the 46 patients interviewed had received treatment from a TBS. ${ }^{137}$

\section{Diarrhoea}

Four studies were identified that reported TCAM product and practitioner use among individuals experiencing diarrhoea. ${ }^{96121} 138139$ A general population study from Kenya ${ }^{139}$ and a paediatric-based survey in Sierra Leone $^{121}$ reported $97.45 \%$ and $31 \%$ of TCAM product use to manage diarrhoea, respectively. In addition to the Kenyan study, similar studies from Mali $(57 \%)^{138}$ and
Nigeria $(11.3 \%)^{96}$ reported rates of TCAM use for diarrhoea management.

\section{Eye diseases}

Seven studies, ${ }^{38}{ }^{140-144}$ five of which were conducted in Nigeria, reported that the TCAM use for ophthalmic conditions ranged from $1.6 \%$ to $83.2 \%$ (average, $28.2 \%$ ). No study presented TCAM practitioner use for the management of ophthalmic conditions.

\section{Surgical care}

Two studies from Nigeria and South Africa reported studies on TCAM product use among surgical patients. In the Nigerian study, $40 \%$ of 60 patients surveyed used herbal medicine during their preoperative period, ${ }^{145}$ while in the South African study 7\% of 495 surgical patients had used TCAM in the preceding 6 weeks. ${ }^{146}$

Others (infantile colic, tuberculosis, oral health and mycetoma) A study in Nigeria reported that $32.8 \%$ and $3.1 \%$ use TCAM product and visited a traditional birth attendant to manage infantile colic, respectively. ${ }^{147}$ Also, studies conducted in Nigeria reported that $10 \%$ and $19.8 \%$ of patients suffering from tuberculosis ${ }^{148}$ and toothache ${ }^{149}$ had consulted with a traditional medicine practitioner, respectively. In addition, another Nigerian study reported that $31.9 \%$ of mothers with sick children visiting a private primary healthcare clinic used crude oil as traditional medication. ${ }^{150}$ In Sudan, $42.4 \%$ of patients with mycetoma reported using herbal medicines, ${ }^{151}$ while $57 \%$ of deceased patients who were terminally ill in Ethiopia visited a traditional and spiritual healer. ${ }^{152}$

\section{General inpatients and outpatients}

Five studies (three Nigerian, one South African and one Ugandan) assessed TCAM use among inpatients and outpatients. The current review indicates a higher TCAM utilisation rate among outpatients compared with inpatients. For instance, a Nigerian study among inpatient and outpatients reported that $72 \%$ of the 200 outpatients are currently using TCAM products, whereas $18.5 \%$ of the 65 inpatients are reportedly using TCAM products. ${ }^{153}$ Similar findings among outpatients were reported in similar studies in Nigeria $(89.9 \%)^{30}$ and South Africa $(60.9 \%)^{154}$ and among inpatients in Nigeria $(14.2 \%)^{155}$ and Uganda $(18.3 \%) .{ }^{156}$

Student population, healthcare professionals and academic staff The reviewed literature indicates that $38.4 \%$ of high school students in Nigeria used a TCAM product ${ }^{157}$ compared with $81.8 \%$ and $75.1 \%$ TCAM product utilisation rates that were reported among Nigerian university students ${ }^{31}$ and university students and staff, ${ }^{158}$ respectively. A similar high utilisation rate was reported among university students in Ghana $(89.1 \%){ }^{35}$ This rate was lower among medical students in both countries (Nigeria: $28 \%^{159}$; Ghana: $56.7 \%^{160}$ ) and among paramedical students in Nigeria (53.9\%). ${ }^{161}$ In Sierra Leone, $59.1 \%$ 
and $55.6 \%$ of graduating medical and nursing students ${ }^{37}$ as well as all pharmacy students ${ }^{36}$ used TCAM products.

Among healthcare professionals, TCAM use was reported among medical doctors in Nigeria $(20.7 \%)^{162}$ and professionals providing HIV/AIDS care in Durban, South Africa $(23.5 \%) .{ }^{163}$ One study drawn from a large sample reported that $50.3 \%$ of the academic and administrative staff in a South African university ${ }^{54}$ used TCAM.

\section{Prevalence of concurrent use of TCAM and allopathic medicines}

Twenty-six papers were identified that reported on the concurrent use of TCAM products and conventional medicines within the general population ${ }^{44} 64164$ and subhealth population. ${ }^{21} 355355668991105106109112117153165-174$ The prevalence of concomitant use ranged from $4.3 \%$ to $69.4 \%$ (mean, $30.5 \%$ ). There is high prevalence of concurrent use with conventional medicine in the general population (mean, 54.9\% (40\%-63.7\%)). The prevalence of co-use of TCAM and allopathic medicines among patients with HIV/AIDS had a mean of $20.3 \%(4.3 \%-47.9 \%))^{21} 5355112166-170173174$ With regard to patients with hypertension, the utilisation rate was higher in a study conducted in Nigeria $(47.5 \%)^{106}$ than in Uganda $(14.3 \%),{ }^{105}$ but a relatively lower utilisation rate $(7 \%)$ was reported among patients with diabetes in Kenya. ${ }^{109}$ Among pregnant women, the prevalence of concurrent use was lower in Kenya $(20 \%)^{89}$ than Uganda $(64.1 \%)^{91}$ and Ghana (45\%). ${ }^{172}$ Among the general outpatients, two studies in Nigeria reported a varied prevalence of $21 \%^{153}$ and $69.4 \% .^{165}$

\section{Sociodemographic profile of TCAM users in the general population}

The sociodemographic characteristics of users of TCAM were identified in a number of articles. TCAM users were reported in many studies to be more common in individuals with a lower socioeconomic status $^{2044456265667179175176}$ and who are unemployed and unskilled ${ }^{20} 6974$ when compared with non-users. With regard to the link between age and TCAM use, the relevant papers reported variability based on where the study was conducted. Generally, studies conducted in urban or semiurban settings reported TCAM users to be younger (20-50 years), ${ }^{20} 58617174$ whereas those conducted in a rural setting reported TCAM users to more likely be older ( $>55$ years) ${ }^{62}{ }^{177}$ An inconsistent pattern was observed from the available literature with respect to educational status of TCAM users. While four included studies reported TCAM users to have little or no formal education, ${ }^{20} 6271177$ two other studies provided a contrasting view. ${ }^{61}{ }^{74}$ Generally, TCAM users compared with non-TCAM users in the general population were more commonly reported to be married ${ }^{44} 4557$ than not married. ${ }^{20}$ Two studies reported on the link between TCAM use and spatial location of respondents. A national household survey in South Africa identified rural residents as more likely to visit a TCAM practitioner than their urban counterparts, ${ }^{20}$ while a study among 324 residents of the Ashanti Region of Ghana did not find any significant difference between TCAM users residing in both locations. ${ }^{50}$ The available literature reports an equivocal relationship between TCAM use and gender. On one hand, two studies from Ethiopia and Nigeria identified women more than men as likely TCAM users, ${ }^{4465}$ while another Nigerian study reported men as likely users of TCAM. ${ }^{45}$ With respect to religion, a community-based study in Enugu, Nigeria reported TCAM users were likely to be Christians than other religions, ${ }^{74}$ whereas another Nigerian study conducted in Imo State did not observe any significant difference. ${ }^{68}$ Meanwhile, two Nigerian studies reported no significant correlation between the sociodemographic characteristics of the respondents and TCAM use. ${ }^{60} 72$

In summary, TCAM users compared with non-TCAM users in the general population across Sub-Saharan Africa are more likely to be of low socioeconomic status, while there were inconsistencies in age, sex, educational status, spatial location and religious affiliation among TCAM users

\section{Sociodemographic profile of TCAM users in health subpopulations}

TCAM users in pregnancy, childbirth and abortion

The reviewed literature shows pregnant women who use TCAM were more likely to be of low socioeconomic status ${ }^{8488929398}$ and less educated ${ }^{84} 8688899298$ compared with non-users, although one study reported higher education completion as a predictor of TCAM use. ${ }^{84}$ TCAM users were also found to be younger $(<30$ years $)^{8498}$ and married ${ }^{8498}$ compared with non-TCAM users. ${ }^{24}$ Meanwhile, three studies from Zambia, ${ }^{82}$ Mali $^{90}$ and Ethiopia ${ }^{83}$ reported no sociodemographic difference between TCAM users and non-users. With regard to TCAM use during childbirth, two studies drawn from a large sample of Nigerian women show TCAM users are likely to be women who are less educated, from low socioeconomic background, Muslim and primiparous. ${ }^{95} 96$ With respect to pregnancy termination, a Tanzanian study indicates that women with primary education from both rural and urban settings were more likely to use herbs to induce abortion compared with those with at least a high school education. ${ }^{97}$

\section{TCAM users among patients with HIV/AIDS}

Patients with HIV/AIDS who identified as a TCAM user in a number of studies across Sub-Saharan Africa were more likely to be female, ${ }^{21} 168178-180$ not married, ${ }^{180} 181$ of low socioeconomic status, ${ }^{21} 180$ younger (<39 years), ${ }^{25} 179180$ unemployed ${ }^{180} 181$ educated, ${ }^{2125}$ from a rural area ${ }^{21} 53$ and of Christian religious denomination. ${ }^{180}$

\section{TCAM users among patients with hypertension and diabetes}

A review of the literature indicates that patients with hypertension who are male, ${ }^{33} 3946$ of low income level, ${ }^{339}$ less educated, ${ }^{33}$ older $^{106}$ and reside in rural area ${ }^{33}$ are more likely to be TCAM users. A Ugandan study did not 
find any significant association between the sociodemographic profile of patients with hypertension and TCAM use. ${ }^{105}$ A study undertaken in South Africa in 2010 found that TCAM users with hypertension compared with non-hypertensive TCAM users were more likely to be older, without a partner and unemployed. ${ }^{104}$ With regard to patients with diabetes, two studies from Kenya ${ }^{109}$ and Nigeria ${ }^{43}$ show that patients with diabetes who are older and have had at least a formal education were more likely to be TCAM users.

\section{TCAM users among patients with cancer}

A Ghanaian study reported that patients with cancer who were female were more likely users of TCAM ${ }^{56}$ whereas a similar study in Ethiopia reported that patients who have attained at least secondary education, had monthly income of more than US $\$ 125$, presented with comorbidity and at the advanced stage of their disease were likely users of TCAM. ${ }^{110}$ However, there were no statistically significant differences between TCAM users and non-users with regard to the type of cancer. Meanwhile, a Nigerian study did not find any significant difference between users and non-users of TCAM. ${ }^{34}$

\section{TCAM users among patients with eye diseases}

Patients with eye problems who are older $(\geq 50$ years), ${ }^{140}{ }^{142}$ from a rural settlement, ${ }^{141} 143$ married ${ }^{141}$ and uneducated $^{142}$ are likely to be TCAM users in Sub-Saharan Africa. However, another study from Nigeria identified younger age ( $<50$ years) as a determinant of TCAM use for eye diseases. ${ }^{141}$ Also, a similar study from Zimbabwe reported traditional medicine users for eye conditions are likely to belong to the Apostolic sect, reside in a periurban area and unemployed. ${ }^{38}$

\section{TCAM users among surgical patients}

The two identified studies from Nigeria and South Africa conducted among presurgical patients found no statistically significant differences exist between TCAM users and non-users. ${ }^{145} 146$

\section{TCAM users among patients with malaria and febrile illness}

Two Sierra Leonean studies reported that TCAM use was associated with being male, ${ }^{120}$ Muslim $^{121}$ and living in a rural area. ${ }^{120}$ In a study conducted among female residents in Nigeria, TCAM users were more likely to be older ( $\geq 50$ years), and less educated, unemployed or had a blue-collar job. ${ }^{118}$

\section{TCAM users presenting with sexual health conditions}

A Ugandan study among patients with sexually transmitted infection reported that TCAM use was common among those who were married and educated. ${ }^{103}$ Ghanaian patients visiting gynaecological units and using TCAM were reported to be less educated and unskilled compared with non-users. ${ }^{94}$ A Zambian study examining the use of TCAM to achieve vaginal dryness prior to sexual intercourse revealed that the practice was common among married women and those who grew up in rural areas. ${ }^{102}$

\section{TCAM users seeking infertility care}

The two identified studies from Nigeria and Uganda indicated that TCAM users were likely to have attained at least secondary education, ${ }^{99} 100$ of low socioeconomic class ${ }^{100}$ married, never conceived and older than 30 years. ${ }^{99}$ The Ugandan study also reported herbal medicine use was higher among women with less than 3 years of infertility. ${ }^{99}$

\section{TCAM users with musculoskeletal diseases}

With regard to musculoskeletal diseases, only one Nigerian study among patients with osteoarthritis was identified, and it reported no significant difference in respondent demographics between TCAM users and non-users. ${ }^{42}$ On the other hand, another Nigerian study that assessed the utilisation of services rendered by TBS reported that being young, male, married, having a skilled occupation and of low economic status were associated with visiting a TBS. ${ }^{134}$

\section{TCAM users with mental illness and neurological disorders}

Two Nigerian studies ${ }^{40} 129$ reported the characteristics of TCAM users with mental health disorders. Caregivers of children with epilepsy who came from low socioeconomic background and had lower levels of education were more likely to use TCAM. ${ }^{40}$ Patients with schizophrenia who are older ( $>40$ years), less educated, reside in a rural setting and practise African traditional religion were more likely to use the services of a traditional healer. ${ }^{129}$ This same study further reported that patients with schizophrenia who are Christians were likely to visit a psychiatric hospital and faith healer compared with their counterparts practising African traditional religion. ${ }^{129}$ Another study from Sudan reported that mental health patients who visit traditional healers were men, with an average age of 31 years, illiterate or with only a primary education, and unemployed. ${ }^{130}$

TCAM users among students, healthcare professionals, academic staff and general outpatient population

A Ghanaian study observed that TCAM users were more likely to be Christians enrolled in non-science-related programmes at the university. ${ }^{35}$ In Sierra Leone, healthcare students' gender, age and year of study were not associated with TCAM use ${ }^{36}{ }^{37}$ although being a Christian was associated with the use of spirituality/prayer among pharmacy students. ${ }^{36}$ With regard to the general outpatient population, a study in Nigeria reported that women who were older, less educated and whose occupation was fishing were more likely to use crude oil as traditional medication. ${ }^{150}$

\section{Drivers of TCAM use}

A handful of papers included in our review identified a number of pull and push factors promoting TCAM use. Key pull factors reported in the literature include 
relative low cost and flexibility of payment of TCAM products and services, ${ }^{29-31} 42 \quad 45 \quad 49 \quad 60 \quad 68 \quad 72-76 \quad 78 \quad 86 \quad 889198 \quad 106$ 108110118134139150161 181-190 accessibility, 22 3031495760727376 8898108118134175183184186187190191

and the perception of

TCAM being natural and therefore safe as well as effective compared with conventional healthcare. ${ }^{2029-32424548}$ 49577374767885868891106108118134139141150157175183187188192

Patients participating in the identified studies were also positively attracted to TCAM for other reasons such as alignment with a patient's sociocultural, religious and spiritual values with regard to health and disease ${ }^{12} 3233$ 426872738191106110118149181183187188190192193 and the sense of patient autonomy of their health. ${ }^{183}$ Other pull factors of TCAM use identified from the literature are patients' trust and confidence in their traditional medicine practitioner to share their personal secrets and the perceived privacy they enjoyed with their traditional medicine practitioner. $^{187} 194$ Perceived psychosocial care and support provided by TCAM providers compared with orthodox healthcare providers have also been reported as a pull factor. $^{98110183}$ In addition, recommendation by respected and trusted peers such as TCAM providers, elders, relatives and friends has also been reported as a factor that drives patients into using TCAM. ${ }^{12} 54111134135161186$ Aggressive advertisement of TCAM products and services is another pull factor. ${ }^{547376186}$

The push factors mainly centred on dissatisfaction with conventional healthcare, and this includes long distance to health facilities, ${ }^{187}$ unavailability of drugs, ${ }^{22} 91186187$ difficulty and inequity in accessing care, ${ }^{22} 91106186$ negative attitude of healthcare providers, ${ }^{106} 134187$ long waiting time, lengthy procedures and fear of being diagnosed of a serious disease. $^{134192}$

\section{Barriers to TCAM use}

A number of population and subpopulation studies reported factors limiting the use of TCAM in Sub-Saharan Africa. Studies conducted among Nigerian ${ }^{31}$ and Sierra Leonean ${ }^{36}$ undergraduate students and Nigerian medical doctors ${ }^{162}$ cited an absence of conclusive scientific evidence that supports TCAM practice as a common barrier to the use of TCAM. A similar finding was reported in a population-based study in Ethiopia. ${ }^{49}$ Also, lack of patient belief in the safety and efficacy of TCAM was identified as a barrier to TCAM use in studies conducted among patients with hypertension, ${ }^{33}$ pregnant women $^{88}$ and patients with various health conditions, ${ }^{192}$ as well as in the general population. ${ }^{49}$ In addition, two population-based studies ${ }^{48} 189$ and a subhealth study ${ }^{192}$ reported that respondents were reluctant to use traditional medical care due to the perceived demonic nature of TCAM. Further, four population-based studies from Ghana $^{183184189}$ and Tanzania ${ }^{73}$ and subpopulation studies from Nigeria ${ }^{31}$ and Ghana ${ }^{192}$ cited perceived lack of an appropriate dose for TCAM products and unhygienic practice in product preparation, 3173183184189 as well as the unregulated TCAM practitioner practice, ${ }^{183} 192$ as deterrent to using TCAM. Other barriers to TCAM use were an absence of health financing for traditional health care ${ }^{183}$ and a perceived lack of education and training among TCAM practitioners. ${ }^{36} 183189$

\section{Non-disclosure of TCAM use to healthcare providers}

Twenty-five subhealth population studies reported on patients' non-disclosure of TCAM use to their conventional healthcare providers. ${ }^{21} 263334394043515256668288$ 8991106 110-112 $145153169194-196$ $100 \%$, with an average of $83.0 \%$. With regard to reasons for non-disclosure, four studies conducted among pregnant women in $\mathrm{Uganda}^{91}$ and Zambia, ${ }^{82}$ patients with hypertension in Ghana ${ }^{39}$ and patients with HIV/AIDS in South Africa ${ }^{195}$ cited fear of receiving improper care as a reason for not disclosing their TCAM use status to their healthcare provider. Another reason for non-disclosure of TCAM use was the conventional medicine provider's negative attitude with perceived lack of support and understanding that lead to mistrust and stigma from conventional providers. Such reasons were put forward by patients with HIV/AIDS in South Africa, ${ }^{194}$ Uganda $^{196}$ and Ghana, ${ }^{51}$ as well as patients with cancer in Nigeria ${ }^{111}$ and pregnant women in Uganda. ${ }^{91}$ The perception among Ethiopian patients with cancer $^{110}$ and Ugandan patients with HIV/AIDS ${ }^{196}$ that their conventional healthcare providers lack knowledge about TCAM was another reason for not divulging their TCAM use status. Healthcare providers' lack of enquiry about TCAM use was also cited among patients with cancer, ${ }^{34}$ epilepsy ${ }^{40}$ and diabetes $^{43}$ in Nigeria. A study in Uganda reported that two-thirds of patients were open for discussion on TCAM use if initiated by their healthcare provider, and majority of them were also willing to adhere to their advice on TCAM use. ${ }^{196}$

\section{Cost of TCAM use}

We identified 15 papers that reported on the cost of

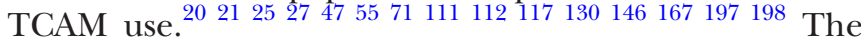
current literature shows a conflicting picture among studies that compared cost incurred between TCAM and conventional care. Some studies suggest that there is relatively low cost involved in using TCAM therapy compared with conventional care, although there is variation on how cost was measured in the two groups. For example, a Ghanaian national survey revealed that the average total household cost in the last 12 months for conventional care was slightly higher (US\$33.43) than costs incurred in seeking TCAM treatment (US\$30.33). ${ }^{27}$ Also, a study conducted among patients with cancer in Nigeria indicates cost of TCAM ranged from no cost to US\$31.25, compared with the minimum cost of US $\$ 250$ for conventional care. ${ }^{111}$ In Mali, half of conventional malaria treatment costs ranged from no cost to US $\$ 116$, whereas TCAM treatment ranged from no cost for three-quarters of patients to US $\$ 100 .^{117}$ In other studies, the cost of TCAM was higher than conventional care. For example, a Cameroonian study reported that the cost of TCAM 
treatment per day (US\$1.5) was higher than conventional treatment (US\$0.77). ${ }^{197}$ Although cost was not stated, Sorketti and colleagues ${ }^{130}$ in Sudan reported that more than three-quarters of psychiatric patients reported that the cost of treatment in traditional health centres was not less than conventional psychiatric service. Although no comparison was made with regard to conventional care, cost for TCAM services was relatively high in certain cases. For instance, in Tanzania, the maximum cost of TCAM treatment for epilepsy was US $\$ 100 .{ }^{119}$ A relatively high cost of TCAM practitioner services was also reported among the general population in South Africa, where the median cost for the last visit to a traditional healer was calculated at US\$21. TCAM costs can take up a significant part of the household healthcare budget. Sixty-four per cent of households in a South African study spent more than $10 \%$ of their monthly spending, ${ }^{20}$ whereas majority (92.2\%) of patients with HIV/AIDS who are TCAM users in Nigeria spent less than $20 \%$ of their monthly income on herbal treatment. ${ }^{112}$ Among surgical patients in South Africa, close to one-third (30\%) paid less than US\$60 for TCAM services. ${ }^{146}$

Findings from studies that assessed the cost per month of TCAM use alone reported an average of US $\$ 47.5$ (US\$12.60-US\$96.88). ${ }^{21} \quad 25 \quad 47 \quad 55 \quad 167 \quad$ In comparison between self-treatment and TCAM practitioner use, the average financial cost in Burkina Faso for TCAM self-care (US\$2.85) was almost half of that for practitioner use (US\$4.77). ${ }^{71}$

\section{Safety of TCAM (self-reported or observed adverse effects)}

Twenty-four papers reported on the perceived adverse effects due to TCAM or in combination with allopathic medicines. ${ }^{33-35} 444752555966697684-8688106110145146153$ 156199200 Fifteen of the studies $33344447697684-8688110145$ 146153199200 reported on the prevalence of respondents' perceived side effects due to TCAM products use $\left(4 \%-53.3 \%\right.$ (mean, 19.1\%)), whereas four ${ }^{35} 66106153$ reported on respondents' perceived side effects due to concomitant use of TCAM products and conventional medicines $(2 \%-56.5 \%$ (mean, $23.5 \%))$. One Nigerian study $^{153}$ among outpatients reported a relatively high prevalence of TCAM adverse effects when used alone $(9 \%)$ than when used in combination with conventional medicine $(2 \%)$. Gastrointestinal disturbances (nausea, vomiting, diarrhoea and abdominal pain) followed by dizziness, headache and malaise were the most common types of adverse effects reported in $11^{344452557684-86145}$ 146153201 of the $12^{34445255597684-86145146153201}$ studies that reported on the types of respondents' perceived side effects. A Ugandan study among patients with HIV/ AIDS and non-HIV/AIDS individuals reported that TCAM use was independently associated with the occurrence of liver fibrosis, ${ }^{59}$ while another among general inpatients indicated that 10 adverse effects were associated with the use of herbal products prior to admission. ${ }^{156}$

\section{DISCUSSION}

This paper reports the first ever systematic review of the available research evidence on the contemporary use of TCAM in Sub-Saharan Africa. While there are assumptions about high use of TCAM (eg, 80\%) across the continent that circulate in the literature, there has been no systematic review to date to substantiate that claim. Our review attempts to provide an estimate of TCAM (product and practitioners) prevalence both in the general population and health subpopulations based on the review of the current literature. The reviewed studies report varied TCAM (product and practitioners) use prevalence rates within and across countries in line with previous reviews. ${ }^{202} 203$ Such variability is possibly attributed to differences in TCAM definition and sample size in different studies and the high tendency for recall bias due to variations in timeframes over which TCAM use was evaluated. For instance, two large Nigerian studies report different prevalence rates of TCAM use during childbirth due to differences in study location, method of sampling and the way TCAM use was assessed. ${ }^{95} 96$ Despite an apparent conflict between variability in reported TCAM utilisation rates across studies, and the high sample size and response rate of many of these studies, our review highlights a relatively high use of TCAM both in the general population and health subpopulations, which resonate with findings of previous studies conducted in developed nations ${ }^{204} 205$ and estimates by the WHO. ${ }^{1}$ The push and pull factors of TCAM use identified in our review also resonate with the drivers of TCAM use reported outside of Africa, ${ }^{206}$ and appear to be important drivers underpinning the high use of TCAM across the continent. As in countries outside of Africa, the high use of TCAM also underscores the substantial role of TCAM as a source of basic healthcare to populations across Africa. It is imperative for health departments and governments across Sub-Saharan Africa to at least consider and inform themselves regarding TCAM, its current role and future possibilities in wider healthcare systems. This can be in the form of TCAM policy design and implementation, promoting TCAM training, research and development, as well as encouraging consideration of the integration of TCAM into mainstream healthcare system. ${ }^{1}$ It is worth noting that as a means of advancing TCAM use, some institutions have integrated TCAM into medical education curriculum within and outside of Africa. ${ }^{6} 207$

Our review also identified a variation in patient non-disclosure rates across studies which resonates with findings from research outside Africa. ${ }^{208}{ }^{209}$ The lowest estimate identified in our review is sufficiently large to warrant concern over communication between patients who are TCAM users and their healthcare providers. Insufficient disclosure of TCAM use also highlights the need to have a clear insight into the barriers to disclosure. The available literature outside of Africa indicates that individual and/ or contextual factors may influence patients' decision not to disclose his/her TCAM use status. ${ }^{208}{ }^{210}$ However, the reasons for non-disclosure identified in our review 
are informed by differences in beliefs and attitudes regarding conventional medicine and TCAM between patients and healthcare providers. In order to improve patient-provider communication about TCAM at the health service delivery level, it is important for healthcare professionals to be aware that their patients are likely users of TCAM and to encourage and facilitate an open dialogue about TCAM use as routine in their interaction with patients. Such communication regarding TCAM should imbibe the culture of shared decision making ${ }^{211}$ about therapeutic options for patients since it promotes patient satisfaction and active patient involvement in their care. ${ }^{212}$ Also, TCAM policy and practice guidelines should incorporate culturally sensitive patient education about the usefulness of patient disclosure of TCAM use to their conventional healthcare providers. In addition, to leverage communication about TCAM use with patients, conventional healthcare providers are required to be knowledgeable about commonly used TCAM products and practices to better advise their patients and the public on their risks and benefits. The current literature, although scanty, indicates a deficiency in knowledge about TCAM products and practices among healthcare providers in Sub-Saharan Africa ${ }^{213} 214$ and outside of Africa. ${ }^{215216}$ As it has been suggested in studies outside of Africa, ${ }^{217} 218$ there is a need for the inclusion of common TCAM modalities into the existing curricula of healthcare training institutions and continuous professional education programme of the various healthcare cadres, as well as making reputable TCAM pharmacopoeias available in health facilities across Africa.

The reasons for the high TCAM patronage across the continent were also examined in our review, and they appear to resonate with the push and pull factors reported in studies conducted outside of Africa. ${ }^{219} 220$ Possible underlying structural factors that help explain the drivers of TCAM use include the fact that Sub-Saharan Africa is host to the largest population of people who are economically disadvantaged, ${ }^{221}$ and access to conventional care is limited due to cost and distance. ${ }^{222}$ Therefore, TCAM offers an affordable and easily accessible healthcare option. Also, because TCAM is publicly available and allows active patient involvement in health decision making, it offers users greater freedom and ownership in terms of their healthcare choices compared with conventional care in which health decisions are generally controlled by the healthcare professional. ${ }^{223}$

Our review also indicates that TCAM was used concurrently with conventional medicine, indicating that TCAM is mostly used as a complementary therapy rather than an alternative to conventional care. This may be linked to a growing paradigm shift among patients towards a holistic attitude in health that aligns with the philosophy of TCAM and acknowledges the insufficiencies of biomedical care. ${ }^{224}$ Given the complex interplay of factors influencing the pluralistic nature of health service utilisation in Sub-Saharan Africa, ${ }^{225}$ further research exploring the factors influencing the decision to use TCAM is required.
The concurrent use of TCAM and allopathic medicines is known to also potentially undermine patient safety and health outcome due to herb-drug interactions leading to serious adverse effect and therapeutic failure of conventional medications. ${ }^{226-228}$ It is imperative that clinical studies be conducted to provide evidence of clinical interactions between conventional medicine and commonly used TCAM modalities in Sub-Saharan Africa. Such information is of value to healthcare providers when interacting with their patients as it will help provide an opportunity for well-informed therapeutic choices to be made that will contribute to maximising patient health outcomes.

Our review indicates a relatively low prevalence of self-reported TCAM adverse effects when used alone or in combination with allopathic medicines compared with what has been reported outside of Africa. Although not verified, it shows that TCAM like any conventional medicine is not free of adverse effects. ${ }^{229}$ The relatively low prevalence may be due to the fact that patient non-disclosure rate across the Sub-Saharan Africa is high and the fact that TCAM is often considered natural and therefore safe. TCAM adverse effects can be due to inherent toxicity or due to quality issues such as poor quality of TCAM products, incorrect or misidentified, or adulterated or contaminated TCAM products. Despite the majority of side effects being reported were gastrointestinal disturbances in our review, serious adverse effects such as liver and kidney toxicities have been cited in the literature. $^{230} 231$ This has led the WHO to develop guidelines for the safety monitoring of herbal medicine product within the existing WHO pharmacovigilance framework. ${ }^{232}$ However, TCAM product safety regulation across Africa is still a challenge as many countries across Africa lack adequate regulatory framework to ensure the safety and quality of TCAM. ${ }^{233}$ Such challenge is compounded by the fact that there are few preclinical and postmarket TCAM safety and quality data as in addition to confusing nomenclature over plant species, varied cultural differences and traditional practices across Africa. ${ }^{234}$ Despite its limitations, the use of pharmacovigilance principles as part of the overall regulatory framework for TCAM in Africa is urgently needed. The incorporation of pharmacovigilance questions into ethnobotanical or ethnopharmacological studies is worth experimenting. ${ }^{235}$ Thus, the systematic collection and analysis of TCAM safety data is crucial in order to protect patients and the public at large.

Our review also identifies, among the general population and some health subpopulations, a relatively high level of self-directed TCAM use compared with the levels of practitioner-directed TCAM use. This may be explained by the significant amount of studies that focused on TCAM product use compared with TCAM practitioner use, or that the decision to use TCAM is more often influenced by family, friends and neighbours than traditional medicine practitioners. ${ }^{12} 111$ National representative studies that specifically look at TCAM 
practitioner utilisation both in general populations and among health subpopulations will provide further insight into the extent of TCAM practitioners' contribution to the health delivery system.

In the general population in particular, the available literature indicates that TCAM users are likely to be of low socioeconomic class who are unemployed and unskilled. This suggests that low socioeconomic status in the society influences the decision to use TCAM given the fact that TCAM is a low-cost healthcare option compared with biomedicine. With particular reference to educational status, the result of the majority of the relevant studies reviewed contrasted with studies from high-income countries that show that TCAM users are more likely to have attained a high level of education than non-users, ${ }^{206} 236237$ but in line with current scholarship in other low and middle-income nations. ${ }^{238}$ The low levels of health literacy ${ }^{239}$ and low access to evidence-based health information across most populations in Sub-Saharan Africa ${ }^{240}$ may explain such correlation. Our review reports conflicting findings on the relationship between TCAM utilisation and age, gender, religion and spatial location. This is in contrast with reviews that focused on studies outside of Africa, particularly with respect to gender in which women were more likely TCAM users compared with men. ${ }^{206} 236{ }^{241}$ Variations in study design, sample size and data analysis may also explain the differences in TCAM user profile across studies, principally where statistical methods employed did not allow for the impact of confounders to be measured, ${ }^{242}$ thereby affecting the validity of the findings. Well-designed nationwide, or multinational, studies in which data are appropriately analysed are required to understand how sociodemographic factors affect TCAM use in and across Sub-Saharan Africa.

Our review highlights that there has been a disproportionate research focus on TCAM use among HIV/ AIDS and obstetric patients in Sub-Saharan Africa. This pattern suggests the current TCAM research priorities in Sub-Saharan Africa and underscores the historic public health policy and research attention dedicated to infectious diseases and maternal child health in Sub-Saharan Africa. ${ }^{243}$ Areas that have received less attention in the TCAM research agenda in Sub-Saharan Africa include cancer, diabetes, musculoskeletal conditions and surgery. Given the steady rise in non-communicable diseases in the region ${ }^{10}$ and the high rate of TCAM use by individuals with these conditions, ${ }^{11} 12$ greater policy attention and research focus are needed to understand TCAM role in non-communicable diseases prevention and treatment in Sub-Saharan Africa. Specifically, well-designed, large-scale studies that look at how TCAM interfaces or interacts with conventional care for non-communicable disease conditions are urgently needed. Also, for both communicable and non-communicable health conditions, the interprofessional dynamics and providerpatient communication with regard to TCAM use need to be further explored.

\section{Review limitations and future research directions}

Our review highlights key research gaps that need to be addressed that currently challenge attempts to provide a comprehensive overview of TCAM use across Sub-Saharan Africa. First, most of the studies in our review were from Nigeria, South Africa and Ghana. Additional data are required from other Sub-Saharan Africa countries where little research has been conducted to know whether findings from less researched countries are in line or in contrast to the current evidence synthesised in our review. Second, of those articles appraised for quality, the majority had critical methodological flaws, such as employing a non-representative sample strategy, reporting a small sample size, incorporating a substantial risk of recall bias and failing to provide a definition of TCAM in their studies, all of which undermine the integrity of research findings and challenge the ability to draw definitive conclusions and conduct proper comparisons across different studies. Similar methodological limitations have been reported elsewhere. ${ }^{236}{ }^{238}$ It is of utmost importance that the quality of empirical research into TCAM use in Sub-Saharan Africa is improved by using standardised methodology that follows good research design and practice. ${ }^{244}$ Third, our review identified the low cost of TCAM as a key driver of TCAM use, and low socioeconomic status was identified as a possible predictor of TCAM use in our review. However, only few studies in our review compared patient-reported cost of TCAM care and conventional healthcare and it shows a conflicting picture. Thus, there is a dearth of research evidence on the actual cost incurred by patients when seeking TCAM care. An economic analysis of TCAM use relative to conventional healthcare in general and subhealth populations is a worthy focus within the future TCAM research agenda in Sub-Saharan Africa. Fourth, the majority of the papers reviewed in our study employed quantitative survey design and analysis, providing a useful snapshot of TCAM utilisation patterns. Such research design, although useful, provides limited information regarding the decision-making process around TCAM use and patient-provider communication about TCAM use. Quantitative survey design also failed to provide an indepth insight with regard to the interface between the lived experience of TCAM use and the user's religion and culture. As such, it is important that qualitative studies that focused on TCAM use and practice are conducted to help provide cultural and social insights that are useful to healthcare providers, policy makers and patients. Fifth, only studies published in English were considered in our review. We decided to include only English papers because none of us are proficient in French and other languages. Given that the full text of each included article is thoroughly read and understood before data are extracted, it will be unwise to rely on the English abstract of papers written in other languages given our limitation in other languages other than English. It is possible that an inclusion of studies published in other languages would have influenced our results. Finally, there are new publications 
beyond our search duration which if included may have influenced our findings. It is good for readers to take this and other aforementioned limitations when interpreting our findings.

\section{CONCLUSION}

TCAM use appears widespread across many countries in Sub-Saharan Africa, although most studies emerge from just a few countries including Nigeria, South Africa, Ghana and Uganda. Stakeholders involved in the healthcare sector in these countries should be mindful of this critical role of TCAM in healthcare service delivery across these countries. Further research in Sub-Saharan Africa should address a number of gaps identified in the current scholarship in order to help inform policy design and practice, as well as contribute to providing safe, efficient and harmonised healthcare for all in Sub-Saharan Africa.

Acknowledgements Successful completion of this manuscript was made possible through participation in the Twelve Weeks to Publication Program funded by Faculty of Health, University of Technology Sydney and with the active support and contributions made by the facilitators and other program participants.

Contributors PBJ and JW conceived of the study. All authors contributed to the study design. PBJ did the database search and data extraction, while JW, AS and JA supervised the process. PBJ wrote the first draft of the manuscript, while JW, AS and JA contributed to the intellectual content and reviewed the subsequent and final drafts of the manuscript.

Funding The authors have not declared a specific grant for this research from any funding agency in the public, commercial or not-for-profit sectors.

Competing interests None declared.

Patient consent Not required.

Provenance and peer review Not commissioned; externally peer reviewed.

Data sharing statement There are no additional data available.

Open access This is an open access article distributed in accordance with the Creative Commons Attribution Non Commercial (CC BY-NC 4.0) license, which permits others to distribute, remix, adapt, build upon this work non-commercially, and license their derivative works on different terms, provided the original work is properly cited, appropriate credit is given, any changes made indicated, and the use is non-commercial. See: http://creativecommons.org/licenses/by-nc/4.0/

\section{REFERENCES}

1. World Health Organization. WHO traditional medicine strategy 2014-2023. Geneva, 2014.

2. World Health Organization. Promoting the role of traditional medicine in health systems: a strategy for the african region, 2000.

3. Bannerman $\mathrm{RH}$. The role of traditional medicine in primary health care. In: Traditional medicine and health care coverage. Geneva: WHO, 1983: 318-27.

4. Mander M, Ntuli L, Diederichs N. Economics of the traditional medicine trade in South Africa: health care delivery. S Afr Health Rev 2007:189-96.

5. Kasilo OM, Trapsida J-M, Mwikisa Ngenda C. An overview of the traditional medicine situation in the African region. African Health Monitor 2010:7-15.

6. Chitindingu E, George G, Gow J. A review of the integration of traditional, complementary and alternative medicine into the curriculum of South African medical schools. BMC Med Educ 2014;14:40

7. KNUST. Programmes of Study, College of Health Sciences. 2018. Available from: https://www.knust.edu.gh/admissions/prospective/ ugprogrammes [Accessed 7 June 2018].

8. Abdullahi AA. Trends and challenges of traditional medicine in Africa. Afr J Tradit Complement Altern Med 2011;8(5 Suppl):115-23.
9. WHO. National policy on traditional medicine and regulation of herbal medicines: report of a WHO global survey. Geneva: World Health Organization, 2005.

10. Dalal S, Beunza JJ, Volmink J, et al. Non-communicable diseases in sub-Saharan Africa: what we know now. Int J Epidemiol 2011;40:885-901.

11. Saydah SH, Eberhardt MS. Use of complementary and alternative medicine among adults with chronic diseases: United States 2002. J Altern Complement Med 2006;12:805-12.

12. Hughes GD, Aboyade OM, Beauclair R, et al. Characterizing herbal medicine use for noncommunicable diseases in urban South Africa. Evidence-Based Complementary and Alternative Medicine 2015;2015:1-10.

13. Ayele AA, Tegegn HG, Haile KT, et al. Complementary and alternative medicine use among elderly patients living with chronic diseases in a teaching hospital in Ethiopia. Complement Ther Med 2017;35:115-9.

14. Sambo L. Health systems and primary health care in the African region. In: African Health Monitor. , 2011: 14, 2-3.

15. Campbell-Hall V, Petersen I, Bhana A, et al. Collaboration between traditional practitioners and primary health care staff in South Africa: developing a workable partnership for community mental health services. Transcult Psychiatry 2010;47:610-28.

16. Adams J, Lui CW, Sibbritt D, et al. Attitudes and referral practices of maternity care professionals with regard to complementary and alternative medicine: an integrative review. $J$ Adv Nurs 2011;67:472-83.

17. Adams J, Barbery G, Lui CW. Complementary and alternative medicine use for headache and migraine: a critical review of the literature. Headache 2013;53:459-73.

18. Peng W, Adams J, Sibbritt DW, et al. Critical review of complementary and alternative medicine use in menopause: focus on prevalence, motivation, decision-making, and communication. Menopause 2014;21:536-48.

19. Fejer R, Kyvik KO, Hartvigsen J. The prevalence of neck pain in the world population: a systematic critical review of the literature. Eur Spine J 2006;15:834-48.

20. Nxumalo N, Alaba O, Harris B, et al. Utilization of traditional healers in South Africa and costs to patients: findings from a national household survey. J Public Health Policy 2011;32 Suppl 1:S124-S136.

21. Peltzer K, Preez NF-du, Ramlagan S, et al. Use of traditional complementary and alternative medicine for HIV patients in KwaZulu-Natal, South Africa. BMC Public Health 2008:8:255.

22. Diaz T, George AS, Rao SR, et al. Healthcare seeking for diarrhoea, malaria and pneumonia among children in four poor rural districts in Sierra Leone in the context of free health care: results of a crosssectional survey. BMC Public Health 2013;13:157.

23. Girma E, Tesfaye M. Patterns of treatment seeking behavior for mental illnesses in Southwest Ethiopia: a hospital based study. BMC Psychiatry 2011;11:138.

24. Mureyi DD, Monera TG, Maponga CC. Prevalence and patterns of prenatal use of traditional medicine among women at selected harare clinics: a cross-sectional study. BMC Complement Altern Med 2012;12:164.

25. Peltzer K, Friend-du Preez N, Ramlagan S, et al. Traditional complementary and alternative medicine and antiretroviral treatment adherence among HIV patients in KwaZulu-Natal, South Africa. Afr J Tradit Complement Altern Med 2010;7.

26. Peltzer K, Preez NF, Ramlagan S, et al. Antiretrovirals and the use of traditional, complementary and alternative medicine by HIV patients in Kwazulu-Natal, South Africa: a longitudinal study. Afr $J$ Tradit Complement Altern Med 2011;8:337-45.

27. Oyebode O, Kandala NB, Chilton PJ, et al. Use of traditional medicine in middle-income countries: a WHO-SAGE study. Health Policy Plan 2016;31:984-91.

28. Peltzer K, Pengpid S. Prevalence and determinants of traditional, complementary and alternative medicine provider use among adults from 32 countries. Chin J Integr Med 2018;24:584-90.

29. Adeyeye O, Onadeko B, Ogunleye O. The use of complementary and alternative medicine by asthma patients receiving care in an urban tertiary centre in Nigeria. Int J Biol Med Res 2011;(4):1026-30 .

30. Adinma E, Azuike E, Okafor-Udah C. Pattern and practice of complimentary and alternative medication amongst patients in a tertiary hospital in Nigeria. Eur J Prev Med 2015;3:44-8.

31. Ahwinahwi U, Chukwudi K. Perception and Use of Complementary and Alternative Medicine (CAM) among undergraduate students in a Nigerian University. J Appl Pharm Sci 2016;6:096-101.

32. Amira OC, Okubadejo NU. Frequency of complementary and alternative medicine utilization in hypertensive patients attending an 
urban tertiary care centre in Nigeria. BMC Complement Altern Med 2007;7:30.

33. Asfaw Erku D, Basazn Mekuria A, Erku DA, Mekuria AB. Prevalence and correlates of complementary and alternative medicine use among hypertensive patients in Gondar Town, Ethiopia. Evid Based Complement Alternat Med 2016;2016:1-7.

34. Ezeome ER, Anarado AN. Use of complementary and alternative medicine by cancer patients at the University of Nigeria Teaching Hospital, Enugu, Nigeria. BMC Complement Altern Med 2007;7:28.

35. Gyasi RM, Agyemang-Duah W, Mensah CM, et al. Unconventional medical practices among Ghanaian students: a university-based survey. J Tradit Complement Med 2017;7:126-32.

36. James PB, Bah AJ, Awareness BAJ. Awareness, use, attitude and perceived need for Complementary and Alternative Medicine (CAM) education among undergraduate pharmacy students in Sierra Leone: a descriptive cross-sectional survey. BMC Complement Altern Med 2014;14:438.

37. James PB, Bah AJ, Kondorvoh IM. Exploring self-use, attitude and interest to study complementary and alternative medicine (CAM) among final year undergraduate medical, pharmacy and nursing students in Sierra Leone: a comparative study. BMC Complement Altern Med 2016;16:121.

38. Jaya $Y$, Masanganise $R$. The prevalence, types and effects of traditional eye medicine use among newly presenting patients at Sekuru Kaguvi Hospital Eye Unit in Harare, Zimbabwe. Cent Afr J Med 2014;60(5-8):36-44.

39. Kretchy IA, Owusu-Daaku F, Danquah S. Patterns and determinants of the use of complementary and alternative medicine: a cross-sectional study of hypertensive patients in Ghana. BMC Complement Altern Med 2014;14:44.

40. Lagunju IA. Complementary and alternative medicines use in children with epilepsy in Ibadan, Nigeria. Afr J Med Med Sci 2013;42:15-23.

41. Mbada CE, Adeyemi TL, Adedoyin RA, et al. Prevalence and modes of complementary and alternative medicine use among peasant farmers with musculoskeletal pain in a rural community in SouthWestern Nigeria. BMC Complement Altern Med 2015;15:164.

42. Obalum DC, Ogo CN. Usage of Complementary and Alternative Medicine (CAM) among osteoarthritis patients attending an urban multi-specialist hospital in Lagos, Nigeria. Niger Postgrad Med $J$ 2011:18:44-7.

43. Ogbera AO, Dada O, Adeyeye F, et al. Complementary and alternative medicine use in diabetes mellitus. West Afr $\mathrm{J}$ Med 2010;29:158-62.

44. Okoronkwo I, Onyia-pat J-lovena, Okpala P, et al. Patterns of complementary and alternative medicine use, perceived benefits, and adverse effects among adult users in Enugu Urban, Southeast Nigeria. Evid Based Complementary Altern Med 2014;2014:1-6.

45. Onyiapat JL, Okoronkwo IL, Ogbonnaya NP. Complementary and alternative medicine use among adults in Enugu, Nigeria. BMC Complement Altern Med 2011;11:19.

46. Osamor PE, Owumi BE. Complementary and alternative medicine in the management of hypertension in an urban Nigerian community. BMC Complement Altern Med 2010;10:36.

47. Oshikoya KA, Senbanjo IO, Njokanma OF, et al. Use of complementary and alternative medicines for children with chronic health conditions in Lagos, Nigeria. BMC Complement Altern Med 2008;8:66.

48. Galabuzi C, Agea J, Fungo B. Traditional medicine as an alternative form of health care system: a pre liminary case study of Nangabo sub-county, central Uganda. Afr J Tradit Complement Altern Med 2010;7:11-16.

49. Gari A, Yarlagadda R, Wolde-Mariam M. Knowledge, attitude, practice, and management of traditional medicine among people of Burka Jato Kebele, West Ethiopia. J Pharm Bioallied Sci 2015;7:136.

50. Gyasi RM, Asante F, Segbefia AY, et al. Does spatial location matter? Traditional therapy utilisation among the general population in a Ghanaian rural and urban setting. Complement Ther Med 2015;23:439-50.

51. Gyasi RM, Tagoe-Darko E, Mensah CM. Use of traditional medicine by HIV/AIDS patients in Kumasi Metropolis, Ghana: a crosssectional survey. Am Int J Contemp Res 2013;4:117-29.

52. Suroowan S, Mahomoodally F. Complementary and alternative medicine use among Mauritian women. Complement Ther Clin Pract 2013;19:36-43.

53. Ekwunife OI, Oreh C, Ubaka CM. Concurrent use of complementary and alternative medicine with antiretroviral therapy reduces adherence to HIV medications. Int J Pharm Pract 2012;20:340-3.

54. van Staden AM, Joubert GB. Interest in and willingness to use complementary, alternative and traditional medicine among academic and administrative university staff in Bloemfontein, South Africa. Afr J Tradit Complement Altern Med 2014;11:61-6.

55. Oshikoya KA, Oreagba IA, Ogunleye OO, et al. Use of complementary medicines among HIV-infected children in Lagos, Nigeria. Complement Ther Clin Pract 2014;20:118-24.

56. Yarney J, Donkor A, Opoku SY, et al. Characteristics of users and implications for the use of complementary and alternative medicine in Ghanaian cancer patients undergoing radiotherapy and chemotherapy: a cross- sectional study. BMC Complement Altern Med 2013;13:16.

57. Abodunrin OL, Omojasola T, Rojugbokan OO. Utilization of alternative medical services by people of a north central city of Nigeria. East Afr J Public Health 2011;8:82-7.

58. Allabi AC, Busia K, Ekanmian V, et al. The use of medicinal plants in self-care in the Agonlin region of Benin. $J$ Ethnopharmacol 2011;133:234-43.

59. Auerbach BJ, Reynolds SJ, Lamorde M, et al. Traditional herbal medicine use associated with liver fibrosis in rural Rakai, Uganda. PLoS One 2012;7:e41737.

60. Bamidele JO, Adebimpe WO, Oladele EA. Knowledge, attitude and use of alternative medical therapy amongst urban residents of Osun State, southwestern Nigeria. Afr J Tradit Complement Altern Med 2009;6:281-8.

61. Banwat ME, A. EA, I. Al, et al. Alternative medicine use among workers in an urban setting in north-central Nigeria. Int $J$ Biomed Res2015;6:268-73.

62. Chintamunnee V, Mahomoodally MF. Herbal medicine commonly used against non-communicable diseases in the tropical island of Mauritius. J Herb Med 2012;2:113-25.

63. De Jager GF, Prinsloo EAM, Joubert G. Use of traditional medicine versus use of the community-based primary health care clinic by the San community at Platfontein. South African Family Practice 2010;52:542-7.

64. Duru CB, Diwe KC, Uwakwe KA. Combined orthodox and traditional medicine use among hous eholds in Orlu, Imo State, Nigeria: prevalence and determinants. World Journal of Preventive Medicine 2016;4:5-11.

65. Flatie T, Gedif T, Asres K, et al. Ethnomedical survey of Berta ethnic group Assosa Zone, Benishangul-Gumuz regional state, mid-west Ethiopia. J Ethnobiol Ethnomed 2009;5:14.

66. Gyasi RM, Siaw LP, Mensah CM. Prevalence and pattern of traditional medical therapy utilisation in Kumasi Metropolis and Sekyere South District, Ghana. J Ethnopharmacol 2015;161:138-46.

67. Mee P, Wagner RG, Gómez-Olivé FX, et al. Changing use of traditional healthcare amongst those dying of HIV related disease and TB in rural South Africa from 2003 - 2011: a retrospective cohort study. BMC Complement Altern Med 2014;14:504.

68. Opara EO KK. Factors affecting utilization of herbal medicine as livelihood alternatives among residents of imo state: the role of social work professionals. J Humanit Soc Sci 2016;21:66-78.

69. Oreagba IA, Oshikoya KA, Amachree M. Herbal medicine use among urban residents in Lagos, Nigeria. BMC Complement Altern Med 2011;11:117.

70. Osemene KP, Elujoba AA, llori MO. A comparative assessment of herbal and orthodox medicines in Nigeria. Niger J Nat Prod Med 2013;17:77-81.

71. Pouliot M. Relying on nature's pharmacy in rural Burkina Faso: empirical evidence of the determinants of traditional medicine consumption. Soc Sci Med 2011;73:1498-507.

72. Sarki ZM DM. Socio-demographic factors and utilization of traditional medicine in Kazaure Town, Jigawa State, Nigeria. Int Journal of Emerging Knowledge 2015;3:9-20.

73. Stanifer JW, Patel UD, Karia F, et al. The determinants of traditional medicine use in northern Tanzania: a mixed-methods study. PLoS One 2015;10:e0122638.

74. Usifoh S, Udezi A. Social and economic factors influencing the patronage and use of complementary and alternative medicine in Enugu. Journal of Pharmacy \& Bioresources 2013;10:17-24.

75. Wassie SM, Aragie LL, Taye BW, et al. Knowledge, attitude, and utilization of traditional medicine among the communities of merawi town, northwest ethiopia: A cross-sectional study. Evid Based Complement Alternat Med 2015;2015:1-7.

76. Jimoh AO, Sani Z, Abubakar K. Safety concerns and determinants of complementary and alternative medicine use in a sub- Concerns and Determinants of Complementary and Alternative Medicine Use in a Sub-urban area of Sokoto, North Western Nigeria. Journal of Medical Sciences 2013;13:737-42.

77. Awad Al, Eltayeb IB, Capps PA. Self-medication practices in Khartoum State, Sudan. Eur J Clin Pharmacol 2006;62:317-24. 
78. Birhan W, Giday M, Teklehaymanot T. The contribution of traditional healers' clinics to public health care system in Addis Ababa, Ethiopia: a cross-sectional study. J Ethnobiol Ethnomed 2011;7:39.

79. Kruk ME, Rockers PC, Varpilah ST, et al. Which doctor?: determinants of utilization of formal and informal health care in postconflict liberia. Med Care 2011:49:585-91.

80. Mathibela MK, Egan BA, Du Plessis HJ, et al. Socio-cultural profile of Bapedi traditional healers as indigenous knowledge custodians and conservation partners in the Blouberg area, Limpopo Province, South Africa. J Ethnobiol Ethnomed 2015;11:49.

81. Mbereko A, Mahlatini P. Understanding contributions of traditional healers to the prevention, care and support in the fight against HIV and AIDS Pandemic in Kariba, Zimbabwe. Int J Sociol Anthropol 2014:6:136.

82. Banda Y, Chapman V, Goldenberg RL, et al. Use of traditional medicine among pregnant women in Lusaka, Zambia. $J$ Altern Complement Med 2007;13:123-8.

83. Bayisa B, Tatiparthi R, Mulisa E. Use of herbal medicine among pregnant women on antenatal care at nekemte hospital, Western ethiopia. Jundishapur J Nat Pharm Prod 2014;9:e17368.

84. Duru CB, Uwakwe KA, Chinomnso NC. Socio-demographic determinants of herbal medicine use in pregnancy among nigerian women attending clinics in a tertiary hospital in Imo State, South-East, Nigeria. American Journal of Medicine Studies 2016;4:1-10.

85. Fakeye TO, Adisa R, Musa IE. Attitude and use of herbal medicines among pregnant women in Nigeria. BMC Complement Altern Med 2009;9:53.

86. Laelago T, Yohannes T, Lemango F. Prevalence of herbal medicine use and associated factors among pregnant women attending antenatal care at public health facilities in Hossana Town, Southern Ethiopia: facility based cross sectional study. Arch Public Health 2016;74:7.

87. Malan DF, Neuba DF. Traditional practices and medicinal plants use during pregnancy by Anyi-Ndenye women (Eastern Côte d'Ivoire). Afr J Reprod Health 2011;15:85-93.

88. Mekuria AB, Erku DA, Gebresillassie BM, et al. Prevalence and associated factors of herbal medicine use among pregnant women on antenatal care follow-up at University of Gondar referral and teaching hospital, Ethiopia: a cross-sectional study. BMC Complement Altern Med 2017;17:86.

89. Mothupi MC. Use of herbal medicine during pregnancy among women with access to public healthcare in Nairobi, Kenya: a crosssectional survey. BMC Complement Altern Med 2014;14:432.

90. Nergard CS, Ho TP, Diallo D, et al. Attitudes and use of medicinal plants during pregnancy among women at health care centers in three regions of Mali, West-Africa. J Ethnobiol Ethnomed $2015 ; 11: 73$

91. Nyeko R, Tumwesigye NM, Halage AA. Prevalence and factors associated with use of herbal medicines during pregnancy among women attending postnatal clinics in Gulu district, Northern Uganda. BMC Pregnancy Childbirth 2016;16:296.

92. Ologe MO, Aboyeji AP, ljaiya MA, et al. Herbal use among pregnant mothers in Ilorin, Kwra State, Nigeria. J Obstet Gynaecol 2008;28:720-1.

93. Tamuno I, Omole-Ohonsi A, Fadare J. Use of herbal medicine among pregnant women attending a tertiary hospital in northern Nigeria.. The Internet Journal of Gynecology and Obstetrics 2011;15.

94. Addo V. Herbal medicines: socio-demographic characteristics and pattern of use by patients in a tertiary obstetrics and gynaecology unit. J Sci Tech 2007;27:149-55.

95. Olusanya BO, Inem VA, Abosede OA. Infants delivered in maternity homes run by traditional birth attendants in urban Nigeria: a community-based study. Health Care Women Int 2011;32:474-91.

96. Sarmiento I, Zuluaga G, Andersson N. Traditional medicine used in childbirth and for childhood diarrhoea in Nigeria's Cross River State: interviews with traditional practitioners and a statewide cross-sectional study. BMJ Open 2016;6:e010417.

97. Rasch V, Kipingili R. Unsafe abortion in urban and rural Tanzania: method, provider and consequences. Trop Med Int Health 2009;14:1128-33.

98. Ebuehi OM, Akintujoye I. Perception and utilization of traditional birth attendants by pregnant women attending primary health care clinics in a rural Local Government Area in Ogun State, Nigeria. Int $J$ Womens Health 2012;4:25-34.

99. Kaadaaga HF, Ajeani J, Ononge S, et al. Prevalence and factors associated with use of herbal medicine among women attending an infertility clinic in Uganda. BMC Complement Altern Med $2014 ; 14: 27$
100. Ola TM, Aladekomo FO, Oludare BA. Determinants of the choice of treatment outlets for infertility in Southwest Nigeria. Rawal Medical Journal 2008;33:193-6.

101. Dienye PO, Judah F, Ndukwu G. Frequency of symptoms and health seeking behaviours of menopausal women in an out-patient clinic in Port Harcourt, Nigeria. Glob J Health Sci 2013;5:39-47.

102. Mbikusita-Lewanika M, Stephen $\mathrm{H}$, Thomas J. The prevalence of the use of 'dry sex' traditional medicines, among Zambian women, and the profile of the users. Psychol Health Med 2009;14:227-38.

103. Nuwaha F, Muganzi E. Predictors of use of traditional medicine by patients with sexually transmitted infections in southwest Uganda. $J$ Altern Complement Med 2008;14:733-9.

104. Hughes GD, Aboyade OM, Clark BL, et al. The prevalence of traditional herbal medicine use among hypertensives living in South African communities. BMC Complement Altern Med 2013;13:38.

105. Nuwaha F, Musinguzi G. Use of alternative medicine for hypertension in Buikwe and Mukono districts of Uganda: a cross sectional study. BMC Complement Altern Med 2013;13:301.

106. Olisa NS, Oyelola FT. Evaluation of use of herbal medicines among ambulatory hypertensive patients attending a secondary health care facility in Nigeria. Int J Pharm Pract 2009;17:101-5.

107. Lunyera J, Wang D, Maro V, et al. Traditional medicine practices among community members with diabetes mellitus in Northern Tanzania: an ethnomedical survey. BMC Complement Altern Med 2016;16:282.

108. Baldé NM, Youla A, Baldé MD, et al. Herbal medicine and treatment of diabetes in Africa: an example from Guinea. Diabetes Metab 2006;32:171-5.

109. Mwangi J, Gitonga L. Perceptions and use of herbal remedies among patients with diabetes mellitus in Murang'a North District, Kenya. Open Journal of Clinical Diagnostics 2014;04:152-72.

110. Erku DA. Complementary and alternative medicine use and its association with quality of life among cancer patients receiving chemotherapy in Ethiopia: a cross-sectional study. Evid Based Complement Alternat Med 2016;2016:8:1-8.

111. Asuzu C, Elumelu-Kupoluyi T, Asuzu M. A pilot study of cancer patients' use of traditional healers in the Radiotherapy Department, University College Hospital, Ibadan, Nigeria. Psycho-Oncol 2015.

112. Onifade AA, Ajeigbe KO, Omotosho IO, et al. Attitude of HIV patients to herbal remedy for HIV infection in Nigeria. Niger $J$ Physiol Sci 2013;28:109-12.

113. Audet CM, Blevins M, Rosenberg C, et al. Symptomatic HIVpositive persons in rural Mozambique who first consult a traditional healer have delays in HIV testing: a cross-sectional study. J Acquir Immune Defic Syndr 2014;66:e80-e86.

114. Horwitz RH, Tsai AC, Maling S, et al. No association found between traditional healer use and delayed antiretroviral initiation in rural Uganda. AIDS Behav 2013;17:260-5.

115. Thielman NM, Ostermann J, Whetten K, et al. Reduced adherence to antiretroviral therapy among HIV-infected Tanzanians seeking cure from the Loliondo healer. J Acquir Immune Defic Syndr 2014;65:e104-e109.

116. Diallo D, Graz B, Falquet J, et al. Malaria treatment in remote areas of Mali: use of modern and traditional medicines, patient outcome. Trans R Soc Trop Med Hyg 2006;100:515-20.

117. Graz B, Willcox M, Berthé D, et al. Home treatments alone or mixed with modern treatments for malaria in Finkolo AC, South Mali: reported use, outcomes and changes over 10 years. Trans $R$ Soc Trop Med Hyg 2015;109:209-13.

118. Jombo GTA, Mbaawuaga EM, Denen AP, et al. Utilization of traditional healers for treatment of malaria among female residents in Makurdi city and its environs. Asian Pac J Trop Biomed 2010;3:563-6.

119. Mensah CM, Gyasi RM. Use of herbal medicine in the management of malaria in the urban-periphery, Ghana. J Biol Agric Healthc 2012;2:113-22.

120. Ranasinghe S, Ansumana R, Lamin JM, et al. Herbs and herbal combinations used to treat suspected malaria in Bo, Sierra Leone. J Ethnopharmacol 2015;166:200-4.

121. Bakshi SS, McMahon S, George A, et al. The role of traditional treatment on health care seeking by caregivers for sick children in Sierra Leone: results of a baseline survey. Acta Trop 2013;127:46-52.

122. Eseigbe EE, Anyiam JO, Ogunrinde GO. Health care seeking behavior among caregivers of sick children who had cerebral malaria in Northwestern Nigeria. Malar Res Treat 2012;2012:4

123. Nwani PO, Arinzechi EO, Asomugha AL, et al. Illness concept among people with epilepsy and their caregivers and preferred treatment methods in a suburban community in Southeast Nigeria. West Afr J Med 2013;32:26-30. 
124. Adeosun II AAA, Adewumi TA, Jeje OO. The pathways to the first contact with mental health services among patients with schizophrenia in Lagos, Nigeria. Schizophr Res Treatment 2013:2013:769161.

125. Aghukwa CN. Care seeking and beliefs about the cause of mental illness among Nigerian psychiatric patients and their families. Psychiatr Serv 2012;63:616-8.

126. Burns JK, Jhazbhay K, Kidd M, et al. Causal attributions, pathway to care and clinical features of first-episode psychosis: a South African perspective. Int J Soc Psychiatry 2011;57:538-45.

127. Ibrahim A, Hor S, Bahar OS, et al. Pathways to psychiatric care for mental disorders: a retrospective study of patients seeking mental health services at a public psychiatric facility in Ghana. Int $J$ Ment Health Syst 2016;10:63.

128. Kauye F, Udedi M, Mafuta C. Pathway to care for psychiatric patients in a developing country: Malawi. Int J Soc Psychiatry 2015;61:121-8.

129. Odinka PC, Oche M, Ndukuba AC, et al. The socio-demographic characteristics and patterns of help-seeking among patients with schizophrenia in south-east Nigeria. $J$ Health Care Poor Underserved 2014;25:180-91.

130. Sorketti EA, Zainal NZ, Habil MH. The characteristics of people with mental illness who are under treatment in traditional healer centres in Sudan. Int J Soc Psychiatry 2012;58:204-16.

131. Tomita A, Burns JK, King H, et al. Duration of untreated psychosis and the pathway to care in KwaZulu-Natal, South Africa. J Nerv Ment Dis 2015;203:222-5.

132. Abbo C. Profiles and outcome of traditional healing practices for severe mental illnesses in two districts of Eastern Uganda. Glob Health Action 2009;4(1-15).

133. Akinpelu A, Oyewole O, Odole A. Prevalence of musculoskeletal pain and health seeking behaviour among occupational drivers in Ibadan, Nigeria. Afr J Biomed Res 2011;14:89-94.

134. Aderibigbe SA, Agaja SR, Bamidele JO. Determinants of utilization of traditional bone setters in Ilorin, north central Nigeria. J Prev Med Hyg 2013;54:35-40.

135. Onyemaechi NO, Lasebikan OA, Elachi IC, et al. Patronage of traditional bonesetters in Makurdi, north-central Nigeria. Patient Prefer Adherence 2015;9:275-9.

136. Nwadiaro H, Ozoilo K, Nwadiaro P, et al. Determinants of patronage of traditional bone setters in the middle belt of Nigeria. Journal of the National Association of Resident Doctors of Nigeria 2008;17:356-9.

137. Aries $\mathrm{MJ}$, Joosten $\mathrm{H}$, Wegdam $\mathrm{HH}$, et al. Fracture treatment by bonesetters in central Ghana: patients explain their choices and experiences. Trop Med Int Health 2007:12:564-74.

138. Farag $\mathrm{TH}$, Kotloff $\mathrm{KL}$, Levine MM, et al. Seeking care for pediatric diarrheal illness from traditional healers in Bamako, Mali. Am J Trop Med Hyg 2013;89(1 Suppl):12-753.

139. Njoroge GN, Kibunga JW. Herbal medicine acceptance, sources and utilization for diarrhoea management in a cosmopolitan urban area (Thika, Kenya). African Journal of Ecology 2007;45(s1):65-70.

140. Achigbu E, Achigbu K. Traditional medication use among outpatients attending the eye clinic of a secondary health facility in Owerri, South-East Nigeria. Orient Journal of Medicine 2014;26(34):107-13.

141. Eze BI, Chuka-Okosa CM, Uche JN. Traditional eye medicine use by newly presenting ophthalmic patients to a teaching hospital in south-eastern Nigeria: socio-demographic and clinical correlates. BMC Complement Altern Med 2009;9:40.

142. Nwosu SN, Obidiozor JU. Incidence and risk factors for traditional eye medicine use among patients at a tertiary eye hospital in Nigeria. Niger J Clin Pract 2011;14:405-7.

143. Ukponmwan CU, Momoh N. Incidence and complications of traditional eye medications in Nigeria in a teaching hospital. Middle East Afr J Ophthalmol 2010;17:315.

144. Ajite KO, Fadamiro OC. Prevalence of harmful/traditional medication use in traumatic eye injury. Glob $\mathrm{J}$ Health Sci 2013;5:55-9.

145. Onyeka TC, Ezike HA, Nwoke OM, et al. Herbal medicine: a survey of use in Nigerian presurgical patients booked for ambulatory anaesthesia. BMC Complement Altern Med 2012;12:130.

146. Nethathe G, Matamba T, Malumalu J, et al. Traditional medicine use in surgical patients in a South African tertiary hospital. South Afr J Anaesth Analg 2016;22:89-92.

147. Oshikoya KA, Senbanjo IO, Njokanma OF. Self-medication for infants with colic in Lagos, Nigeria. BMC Pediatr 2009;9:9.

148. Ukwaja KN, Alobu I, Nweke CO, et al. Healthcare-seeking behavior, treatment delays and its determinants among pulmonary tuberculosis patients in rural Nigeria: a cross-sectional study. BMC Health Serv Res 2013;13:25.
149. Lawal FB, Taiwo JO, Oke GA. Factors influencing awareness and attendance of traditional oral health care practices by residents of a peri-urban community in Ibadan, Nigeria. Afr Health Sci 2015;15:233-9.

150. Dienye P, Akani A, Itimi K. Uses of crude oil as traditional medicine: a survey of mothers in a rural clinic in South-south Nigeria. Rural Remote Health 20121858:12.

151. Ezaldeen EA, Fahal AH, Osman A. Mycetoma herbal treatment: the mycetoma research centre, Sudan experience. Plos Neglect Trop Dis 2013;7:e2400.

152. Reniers G, Tesfai R. Health services utilization during terminal illness in Addis Ababa, Ethiopia. Health Policy Plan 2009;24:312-9.

153. Fakeye TO, Tijani A, Adebisi O. A survey of the use of herbs among patients attending secondary-level health care facilities in Southwestern Nigeria. J Herb Pharmacother 2008;7(3-4):213-27.

154. Marais A, Steenkamp V, Du Plooy WJ. Conditions frequently selftreated with herbal remedies by patients visiting a tertiary hospital in Gauteng, South Africa. S Afr Fam Pract 2015;57:8-11.

155. Fakeye TO, Adisa R, Olatunji E. Self medication among hospitalized patients in selected secondary health facilities in South Western Nigeria. J Pharm Pract 2010;8:233-7.

156. Kiguba R, Ononge S, Karamagi $\mathrm{C}$, et al. Herbal medicine use and linked suspected adverse drug reactions in a prospective cohort of Ugandan inpatients. BMC Complement Altern Med 2016;16:145.

157. Alade GO, Okpako E, Ajibesin KK, et al. Indigenous knowledge of herbal medicines among adolescents in Amassoma, Bayelsa State, Nigeria. Glob J Health Sci 2016;8:217.

158. Nworu CS, Udeogaranya PO, Okafor CK, et al. Perception, usage and knowledge of herbal medicines by students and academic staff of University of Nigeria: A survey. European Journal of Integrative Medicine 2015;7:218-27.

159. Enwere OO. Herbs in orthodox practice: a view by medical students. Afr J Tradit Complement Altern Med 2009;6:203-6.

160. Ameade EP, Amalba A, Helegbe GK, et al. Medical students' knowledge and attitude towards complementary and alternative medicine - A survey in Ghana. J Tradit Complement Med 2016;6:230-6.

161. Adomi PO. Herbal medicine usage by paramedical students of Delta State University Abraka, Nigeria. Australian Journal of Herbal Medicine 2014;26:114-8.

162. Awodele O, Agbaje EO, Abiola OO, et al. Doctors' attitudes towards the use of herbal medicine in Lagos, Nigeria. Journal of Herbal Medicine 2012;2:16-22.

163. Mbutho NP, Gqaleni N, Korporaal CM. Traditional complementary and alternative medicine: knowledge, attitudes and practices of health care workers in HIV and AIDS clinics in Durban hospitals. Afr J Tradit Complement Altern Med 2012;9(3 Suppl):64-72.

164. Chingwaru W, Prevalence VJ. perceptions and factors influencing the use of traditional and complementary medicine (T\&CM) in Zimbabwe's adult population: The case of Bindura District. Eur J Integr Med 2016;8:484-93.

165. ADIBE M. Prevalence of concurrent use of herbal and synthetic medicines among outpatients in a mission hospital in Nigeria. Int $J$ Drug Dev Res 2009.

166. Awodele O, Olayemi SO, Adeyemo TA, et al. Use of complementary medicine amongst patients on antiretroviral drugs in an HIV treatment centre in Lagos, Nigeria. Curr Drug Saf 2012;7:120-5.

167. Babb DA, Pemba L, Seatlanyane $P$, et al. Use of traditional medicine by HIV-infected individuals in South Africa in the era of antiretroviral therapy. Psychol Health Med 2007;12:314-20.

168. Langlois-Klassen D, Kipp W, Jhangri GS, et al. Use of traditional herbal medicine by AIDS patients in Kabarole District, western Uganda. Am J Trop Med Hyg 2007;77:757-63.

169. Lubinga SJ, Kintu A, Atuhaire J, et al. Concomitant herbal medicine and Antiretroviral Therapy (ART) use among HIV patients in Western Uganda: a cross-sectional analysis of magnitude and patterns of use, associated factors and impact on ART adherence. AIDS Care 2012:24:1375-83

170. Malangu N. Self-reported use of traditional, complementary and over-the-counter medicines by HIV-infected patients on antiretroviral therapy in Pretoria, South Africa. Afr $J$ Tradit Complement Altern Med 2007;4:273-8.

171. Stanifer JW, Lunyera J, Boyd D, et al. Traditional medicine practices among community members with chronic kidney disease in northern Tanzania: an ethnomedical survey. BMC Nephrol 2015:16:170.

172. Aryeetey R, Aikins M, Dako-Gyeke P, et al. Pathways utilized for antenatal health seeking among women in the Ga East District, Ghana. Ghana Med J 2015;49:44-9.

173. Mncengeli S, Manimbulu NM, Panjasaram N. Concurrent use of Antiretroviral and African traditional medicines amongst people 
living with HIV/AIDS (PLWA) in the eThekwini Metropolitan area of KwaZulu Natal. Afr Health Sci 2016;16:1118-30.

174. Tamuno I. Traditional medicine for HIV infected patients in antiretroviral therapy in a tertiary hospital in Kano, Northwest Nigeria. Asian Pac J Trop Med 2011;4:152-5.

175. Gyasi RM, Mensah CM, Siaw LP. Predictors of traditional medicines utilisation in the Ghanaian health care practice: interrogating the Ashanti situation. J Community Health 2015;40:314-25.

176. Sato A. Does socio-economic status explain use of modern and traditional health care services? Soc Sci Med 2012;75:1450-9.

177. Ladele AA, Bisi-Amosun OO. Level of utilization of traditional and orthodox medicines by rural dwellers in lle-Ogbo Community of Osun State, Nigeria. Journal of Agricultural Extension 2014;18:155-68.

178. Monera TG, Maponga CC. Prevalence and patterns of Moringa oleifera use among HIV positive patients in Zimbabwe: a crosssectional survey. Journal of public Health in Africa 2012;3:6.

179. Namuddu B, Kalyango JN, Karamagi C, et al. Prevalence and factors associated with traditional herbal medicine use among patients on highly active antiretroviral therapy in Uganda. BMC Public Health 2011;11:855.

180. Nlooto M, Naidoo P, Traditional NP. Traditional, complementary and alternative medicine use by HIV patients a decade after public sector antiretroviral therapy roll out in South Africa: a cross sectional study. BMC Complement Altern Med 2016;16:128.

181. Otang WM, Grierson DS, Prevalence NRN. perceived benefits and effectiveness of herbal medicine in the management of symptoms of opportunistic fungal infections in HIV/AIDS patients in the Eastern Cape, South Africa. Afr J Biotechnol 2011;10:19458-63.

182. Akeju DO, Oladapo OT, Vidler M, et al. Determinants of health care seeking behaviour during pregnancy in Ogun State, Nigeria. Reprod Health 2016;13 Suppl 1:32.

183. Gyasi RM, Asante F, Yeboah JY, et al. Pulled in or pushed out? Understanding the complexities of motivation for alternative therapies use in Ghana. Int J Qual Stud Health Well-being 2016;11:29667.

184. Gyasi RM, Mensah CM, Adjei PO-W, et al. Public perceptions of the role of traditional medicine in the health care delivery system in Ghana. Glob J Health Sci 2011;3:40-9.

185. Kaingu CK, Oduma JA, Kanui TI. Practices of traditional birth attendants in Machakos District, kenya. J Ethnopharmacol 2011;137:495-502.

186. Rutebemberwa E, Lubega M, Katureebe SK, et al. Use of traditional medicine for the treatment of diabetes in Eastern Uganda: a qualitative exploration of reasons for choice. BMC Int Health Hum Rights 2013;13:1

187. Mwaka AD, Okello ES, Orach CG. Barriers to biomedical care and use of traditional medicines for treatment of cervical cancer: an exploratory qualitative study in northern Uganda. Eur $\mathrm{J}$ Cancer Care 2015;24:503-13.

188. Okafor IP, Sekoni AO, Ezeiru SS, et al. Orthodox versus unorthodox care: a qualitative study on where rural women seek healthcare during pregnancy and childbirth in Southwest, Nigeria. Malawi Med J 2014;26:45-9.

189. Tabi MM, Powell M, Hodnicki D. Use of traditional healers and modern medicine in Ghana. Int Nurs Rev 2006;53:52-8.

190. Scott K, McMahon S, Yumkella F, et al. Navigating multiple options and social relationships in plural health systems: a qualitative study exploring healthcare seeking for sick children in Sierra Leone. Health Policy Plan 2014;29:292-301.

191. Gyasi RM. Relationship between health insurance status and the pattern of traditional medicine utilisation in Ghana. Evid Based Complement Alternat Med 2015;2015:1-10.

192. Aziato L, Antwi HO. Facilitators and barriers of herbal medicine use in Accra, Ghana: an inductive exploratory study. BMC Complement Altern Med 2016;16:142.

193. Appelbaum Belisle H, Hennink M, Ordóñez CE, et al. Concurrent use of traditional medicine and ART: perspectives of patients, providers and traditional healers in Durban, South Africa. Glob Public Health 2015;10:71-87.

194. Puoane TR, Hughes GD, Uwimana J, et al. Why HIV positive patients on antiretroviral treatment and/or cotrimoxazole prophylaxis use traditional medicine: perceptions of health workers, traditional healers and patients: a study in two provinces of South Africa. Afr J Tradit Complement Altern Med 2012;9:495-502.

195. Hughes GD, Puoane TR, Clark BL, et al. Prevalence and predictors of traditional medicine utilization among persons living with AIDS (PLWA) on antiretroviral (ARV) and prophylaxis treatment in both rural and urban areas in South Africa. Afr J Tradit Complement Altern Med 2012;9:470-84.
196. Langlois-Klassen D, Kipp W, Rubaale T. Who's talking? Communication between health providers and HIV-infected adults related to herbal medicine for AIDS treatment in western Uganda. Soc Sci Med 2008:67:165-76.

197. Labhardt ND, Aboa SM, Manga E. Bridging the gap: how traditional healers interact with their patients. A comparative study in Cameroon. Trop Med Int Health 2010; 15;(9):1099-108.

198. Winkler AS, Mayer M, Ombay M. Attitudes towards African traditional medicine and Christian spiritual healing regarding treatment of epilepsy in a rural community of northern Tanzania. Afr $J$ Tradit Complement Altern Med 2009;7:162-70.

199. Moshabela M, Pronyk P, Williams N, et al. Patterns and implications of medical pluralism among HIV/AIDS patients in rural South Africa. AIDS Behav 2011;15:842-52.

200. Awodele O, Amagon K, Usman S, et al. Safety of herbal medicines use: case study of ikorodu residents in Lagos, Nigeria. Curr Drug Saf 2013;9:138-44.

201. Tchacondo T, Karou SD, Batawila K, et al. Herbal remedies and their adverse effects in Tem tribe traditional medicine in Togo. Afr $J$ Tradit Complement Altern Med 2011:8:45-60.

202. Ernst E. Prevalence surveys: to be taken with a pinch of salt. Complement Ther Clin Pract 2006;12:272-5.

203. Hall HG, Griffiths DL, McKenna LG. The use of complementary and alternative medicine by pregnant women: a literature review. Midwifery 2011;27:817-24.

204. Clarke TC, Black LI, Stussman BJ. Trends in the use of complementary health approaches among adults: United States, 2002-2012. Natl Health Stat Report 2015;79:1.

205. Xue CC, Zhang AL, Lin V, et al. Complementary and alternative medicine use in Australia: a national population-based survey. $J$ Altern Complement Med 2007:13:643-50.

206. Reid R, Steel A, Wardle J, et al. Complementary medicine use by the Australian population: a critical mixed studies systematic review of utilisation, perceptions and factors associated with use. BMC Complement Altern Med 2016;16:176.

207. Quartey NK, Ma PH, Chung VC, et al. Complementary and alternative medicine education for medical profession: systematic review. Evid Based Complement Alternat Med 2012;2012:13.

208. Davis EL, Oh B, Butow PN, et al. Cancer patient disclosure and patient-doctor communication of complementary and alternative medicine use: a systematic review. Oncologist 2012;17:1475-81.

209. Robinson A, McGrail MR. Disclosure of CAM use to medical practitioners: a review of qualitative and quantitative studies. Complement Ther Med 2004;12(2-3):90-8.

210. Thomson P, Jones J, Evans JM, et al. Factors influencing the use of complementary and alternative medicine and whether patients inform their primary care physician. Complement Ther Med 2012;20(1-2):45-53.

211. Salzburg Global Seminar. Salzburg statement on shared decision making. BMJ 2011;342:d1745.

212. Oh B, Butow P, Mullan B, et al. Patient-doctor communication: use of complementary and alternative medicine by adult patients with cancer. J Soc Integr Oncol 2010;8:56-64.

213. Asmelashe Gelayee D, Binega Mekonnen G, Asrade Atnafe S, et al. Herbal medicines: personal use, knowledge, attitude, dispensing practice, and the barriers among community pharmacists in Gondar, Northwest Ethiopia. Evid Based Complement Alternat Med 2017;2017:6480142:1-6.

214. Fakeye TO, Onyemadu O. Evaluation of knowledge base of hospital pharmacists and physicians on herbal medicines in Southwestern Nigeria. Pharm Pract 2008;6:88.

215. Suchard JR, Suchard MA, Steinfeldt JL. Physician knowledge of herbal toxicities and adverse herb-drug interactions. Eur J Emerg Med 2004;11:193-7.

216. Wahner-Roedler DL, Lee MC, Chon TY, et al. Physicians' attitudes toward complementary and alternative medicine and their knowledge of specific therapies: 8-year follow-up at an academic medical center. Complement Ther Clin Pract 2014;20:54-60.

217. Kemper KJ, Gardiner P, Gobble J, et al. Expertise about herbs and dietary supplements among diverse health professionals. BMC Complement Altern Med 2006;6:15.

218. Clement YN, Williams AF, Khan K, et al. A gap between acceptance and knowledge of herbal remedies by physicians: the need for educational intervention. BMC Complement Altern Med 2005;5:20.

219. Sibbritt D, Adams J, Murthy V. The prevalence and determinants of Chinese medicine use by Australian women: analysis of a cohort of 10,287 women aged 56-61 years. Am J Chin Med 2013;41:281-91.

220. Magin PJ, Adams J, Heading GS, et al. Complementary and alternative medicine therapies in acne, psoriasis, and atopic eczema: results of a qualitative study of patients' experiences and perceptions. J Altern Complement Med 2006;12:451-7. 
221. Cruz M, Foster J, Quillin B. Ending extreme poverty and sharing prosperity: Progress and policies. Policy Research Note PRN/15/03, World Bank Group 2015.

222. Peters DH, Garg A, Bloom G, et al. Poverty and access to health care in developing countries. Ann N Y Acad Sci 2008;1136:161-71.

223. Bishop FL, Yardley L, Lewith GT. A systematic review of beliefs involved in the use of complementary and alternative medicine. $J$ Health Psychol 2007;12:851-67.

224. Stratton TD, McGivern-Snofsky JL. Toward a sociological understanding of complementary and alternative medicine use. $J$ Altern Complement Med 2008;14:777-83.

225. Olsen WC, Sargent C. African Medical Pluralism. Indianapolis: Indiana University Press, 2017.

226. Izzo AA, Ernst E. Interactions between herbal medicines and prescribed drugs: an updated systematic review. Drugs 2009;69:1777-98.

227. Kamsu-Foguem B, Foguem C. Adverse drug reactions in some African herbal medicine: literature review and stakeholders interview. Integr Med Res 2014;3:126-32.

228. Luyckx VA, Naicker S. Acute kidney injury associated with the use of traditional medicines. Nat Clin Pract Nephrol 2008;4:664-71.

229. Delgoda R, Ellington C, Barrett S, et al. The practice of polypharmacy involving herbal and prescription medicines in the treatment of diabetes mellitus, hypertension and gastrointestinal disorders in Jamaica. West Indian Med J 2004;53:400-5.

230. Nortier JL, Vanherweghem JL. For patients taking herbal therapy-lessons from aristolochic acid nephropathy. Nephrol Dial Transplant 2007:22:1512-7.

231. Oshikoya KA, Njokanma OF, Chukwura HA, et al. Adverse drug reactions in Nigerian children. Paediatr Perinat Drug Ther 2007;8:81-8.

232. WHO. WHO guidelines on safety monitoring of herbal medicines in pharmacovigilance systems. 2004. Geneva: World Health Organization vii, 2015.
233. Kasilo OM, Trapsida J-M, régional pour l'Afrique B. Regulation of traditional medicine in the WHO African region. African Health Monitor 2010:25-31.

234. Adewunmi CO, Ojewole JAO. Safety of traditional medicines, complementary and alternative medicines in Africa. Afr $\mathrm{J}$ Tradit Complement Altern Med 2006;1:1-3.

235. Rodrigues E, Barnes J. Pharmacovigilance of herbal medicines. Drug Saf 2013;36:1-12.

236. Seo HJ, Baek SM, Kim SG, et al. Prevalence of complementary and alternative medicine use in a community-based population in South Korea: a systematic review. Complement Ther Med 2013;21:260-71.

237. Ernst E. Prevalence of use of complementary/alternative medicine: a systematic review. Bull World Health Organ 2000;78:258-66.

238. Suswardany DL, Sibbritt DW, Supardi S, et al. A critical review of traditional medicine and traditional healer use for malaria and among people in malaria-endemic areas: contemporary research in low to middle-income Asia-Pacific countries. Malar J 2015;14:98.

239. Thompson J, Havenga Y, Naude S. The health literacy needs of women living with HIV/AIDS. Health SA Gesondheid 2015;20:11-21.

240. Forland F, Rohwer AC, Klatser P, et al. Strengthening evidencebased healthcare in Africa. Evid Based Med 2013;18:204-6.

241. Frass M, Strassl RP, Friehs $\mathrm{H}$, et al. Use and acceptance of complementary and alternative medicine among the general population and medical personnel: a systematic review. Ochsner $J$ 2012;12:45-56

242. Greenland S, Morgenstern H. Confounding in health research. Annu Rev Public Health 2001;22:189-212.

243. World Health Organization Regional Office for Africa. The health of the people: the African regional health report. World Health Organization, 2006

244. Vandenbroucke JP, von Elm E, Altman DG, et al. Strengthening the Reporting of Observational Studies in Epidemiology (STROBE): explanation and elaboration. PLoS Med 2007;4:e297. 